\title{
Eddy Transport in Liquid-Metal Heat Tranefer
}

\section{by}

O. E. Dwyer

\section{Brookhaven Nattonal Laboratory Upton, New York}

\begin{abstract}
This paper was submitted for publication in the open literature at least 6 months prior to the issuance date of this Microcard. Since the U.S.A.E.C. has no evidence that it has been published, the paper is being distributed in Microcard form as a preprint.
\end{abstract}

February 18, 1962

(Submitted to A. I. Ch. E. Journal for publication)
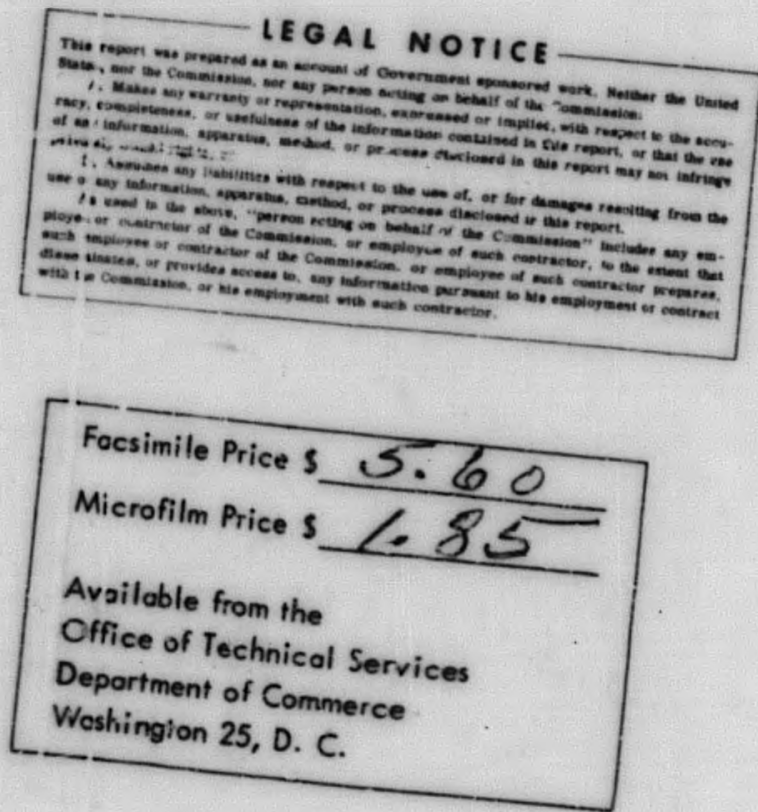


\section{ABSTRACT}

There are certain semi-empirical equations for estimating heat transfer coefficients for liquid metals flowing through regular shapes. These contain the factor $\bar{\psi}$, which is the average, effective value of the ratio of the eddy diffusivity of heat transler to that for momentum trans fer. The main proble:m in lifuid metal heat transfer has been to evaluate this quantity. It is here proposed that this be done by an equation of the type

$$
\bar{\psi}=1-\frac{\frac{a}{\mathrm{Pr}}-c}{\left(\epsilon_{M} / \nu\right)_{\max }^{\mathrm{m}}}
$$

There are insufficient experimental results available to evaluate all three constants, but there is good reason to belleve that $\mathrm{c}$ is small compared to the a/Pr term and can be neglected. On this basts, it is recommended that a equal 1.82 and $\mathrm{m}, 1.4$. With these constants, the above eq ation is found to give values of $\bar{\psi}$, which, when incorporated in the se ni-empirical equations for estimating liquid-metal heat transfer coeff tclents, bring theoretical predictions and experimental results into good agreement for flow through circular tubes, concentric annuli, and rod bundles. 


\section{INTRODUCTION}

In the cooling and heating of turbulently flowing fluids, in a circular pipe, heat is transferred in the radial direction by two mechanisms: molecular conduction and eddy transport. Small particles of fluid having velocity components in the $y$ direction, 1.e., perpendicular to the wall, transport sensible heat from their points of origin to their points of rest, or disappearance. These eddies also, of course, transport momentum.

In liquid-metal heat transfer analysis, the real problem has been to assess properly the eddy transport contribution in the total rate of heat transfer. In early theoretical studies of liquid-metal heat transfer, the eddy diffusivity of heat transfer was either assumed equal to that for momentum transfer or simply treated as a parameter, whose values were unknown. Nelther of these approaches led to theoretical relationships which could be relled upon to predict liquid-metal heat transfer rates with desired accuracy. There have been several attempts $(1,2,3,4)$ to produce a rational method of evaluating the contribution of eddy diffusivity transport in liquidmetal heat transfer; but these have not wholly succeeded, thus tar, in reconclling the differences which are usually found between theoretical predictions and experi mental results.

This paper represents yet another attempt to reconclle these differences by a still different attack on the eddy diffusivity problem. The purpose is to 
develop a practical method of evaluating the eddy diffusivity of heat trarsfer for liquid metals, so that it can be incorporated into the more or less standard theoretical methods to give heat transfer coefficients which are in reasonable agreement with the experimental facts.

\section{THEORETICAL CONSIDERATIONS}

In the foilowing treatment, we shall consider the component of the eddy velocity in the mean-flow, or $\mathrm{x}$, direction, $\mathrm{u}^{\prime}$; and that perpendicular to the mean flow, or y direction, $v^{\prime}$. Next, we employ Prandtl's (5) mixinglength theory which defines the mixing length by the equation

$$
u^{\prime}=\ell \frac{d u}{d y}
$$

where $f$ is the instantaneous mixing length. And next, we write the definttion of eddy diffusivity of heat transfer, whlch is

$$
\epsilon_{\mathrm{H}} \equiv \mathrm{f}_{\mathrm{H}} \mathrm{fv}^{\prime}
$$

where the term $t_{H}$ represents the ratio of the heat which the eddy actually transported through the distance $l$ compared to what it could have transported if it did not lose any in transit. Since liquid metais have high molecular thermal conductivities, the eddies may lose a good portion of their heat to the surrounding liquid by both conduction and convection. The traction 
lost $\left(1-t_{H}\right)$ will, of course, vary with, a mong other things, the speed at which the eddy travels and the thermal conductivity of the liquid metal. For circular conduits, the author estimates that at the low end of the tur.bulent llow regime, the eddies appear to lose essentially all their heat while In transit, whereas at Peclet numbers above 5000 , which would correspond to a Reynglds number of about 250,000 for mercury and 700,000 for sodium, the eddies appear to lose an insignificant fraction of their heat.

For-fully-developed flow in a round tube, the heat flux across an Imaginary cylindrical surface, coaxtal with the axis of the tube, by eddy conduction would be

$$
q=t_{H^{\ell}} v^{\prime} C_{p} \rho \frac{d t}{d r}
$$

The lost flux at that particular radius would then be

$$
\left(1-t_{H^{\prime}}\right)\left(v^{\prime} C_{p} \rho \frac{d t}{d r}\right.
$$

The rate of heat loss by an individual eddy would be

$$
h\left(t_{e^{-t}}\right)^{(\text {surface a rea of eddy })}
$$

where $t_{e}$ and $t$ are the temperatures of the eddy and surrounding fluid, respectively. It can be assumed that the number of eddies per unit volums of fluid is proportional to the tube Reynolds number, or the eddy Reyrolds 
number, $\epsilon_{M} / \nu$, ralsed to some power. Making this assumption, we can combine equations ( 4$)$ and (5) to give

$$
\left(1 f_{H}\right) \rho v^{\prime} C_{p} \rho \frac{d t}{d r}=\left(a \text { constant } h \left(t e^{-t)\left(\epsilon_{N} / \nu\right)^{n}}\right.\right.
$$

Drawing an analogy between velocity and temperature, as tar as eddy properties are concerned, we can write the equation

$$
t^{-t}=l \frac{d t}{d r}
$$

which is ara logous to equation (1). Also, we can write the equation

$$
h=\stackrel{k}{b}
$$

where $k$ is the molecular conductivity, and $b$ represents the effective thickness of the $111 \mathrm{~m}$, around the eddy, through which the heat must be transferred. Equation (8) assumes that the eddy itself moves in stream-line motion with respect to the surrounding medium. Stream-line conditions were assumed, not because all the eddies move in this fashion, but because, for all pract:cal purposes, it seems logical to assume that those which lose their heat are the ones which are moving more slowly and most probably in the viscous tlow regime.

Combining equations (6), (7), and (8) now gives

$$
\left(1-\mathbf{f}_{\mathrm{H}}\right) \mathrm{C}_{\mathrm{p}} \rho v^{\prime}=(\mathrm{a} \text { constant }){ }_{i j}^{\mathrm{s}}\left(\epsilon_{\mathrm{M}} / \nu\right)^{\mathrm{n}}
$$


The definition of Nusselt number implies that the film thickness b ts proportional to the particle diameter, and in turbulence, the eddy diameter is generally assumed to be proportional to $\ell$.

It ts now necessary to write the definttion of eddy diffusivity for momentum transfer. It is

$$
\epsilon_{M}=l_{M} l^{\prime}
$$

With these relationships, equation (9) can be reduced to

$$
\ell_{H}=\frac{1}{1+\frac{a\left(\epsilon_{M} / \nu\right)^{n-1}}{(\mathrm{Pr}) \psi}}
$$

where $\underline{\mathrm{a}}=\mathrm{a}$ constant, and

$$
\psi=\frac{\epsilon_{H}}{\epsilon_{M}}=\frac{t_{H}}{t_{M}}
$$

An analogous treatment will now be given for the eddy diffusivity of momentum transter.

The shearing stress, due to momentum transfer by eddy diffusion, a long an imaginary cylindrical surface at any radius in turbulent pipe flow is given by the equation

$$
\tau=\frac{l_{M}^{l v^{\prime} \rho}}{B_{0}} \frac{d u}{d r}
$$


The momentum which is logt in transit is then

$$
\frac{\left(1-t_{M}\right) e v F}{g_{0}} \frac{d u}{d r}
$$

This can be related to the drag on the particle of fluid, which for viscous

flow of the surrounding fluid is

$$
\mathbf{F}=\frac{3 \pi \mathbf{d}_{o} i \mathrm{v}^{\prime}}{g_{0}}
$$

The shearing stress on the particle becomes proportional to $F / d_{0}{ }^{2}$, or to

$$
\frac{3 \pi u v^{\prime}}{g_{0} d_{0}}
$$

Equations (14) and (16) can now be combined, and the term $\left(\epsilon_{M} / \nu\right)^{n}$ incorporated as in equation (6), to give the equation

$$
1-t_{M}=(a \text { constant }) \frac{\mu}{\rho v^{\prime} d_{0}}\left(\epsilon_{M} / \nu\right)^{n}
$$

Remembering that the actual particle Reynoids number

$$
\frac{d_{0} v^{\prime} \rho}{u}=(a \text { constant }) \frac{\epsilon_{M} / \nu}{f_{M}}
$$

equation (17) can then be reduced to

$$
f_{M}=\frac{1}{1+c\left(\epsilon_{M} / \nu\right)^{n-1}}
$$


where $c$ equals a constant. Finally, substituting equations (11) and (19) Into (12), and simplifying, we get

$$
v=1-\frac{\frac{\mathrm{a}}{\mathrm{Pr}}-\mathrm{c}}{\left(\epsilon_{\mathrm{N}} / \nu^{\mathrm{m}}\right.}
$$

This equation has three constants, a, c, and $\mathrm{m}$. For a given Prandtl numher, however, it simplifies to

$$
\psi=\left[1-\frac{A}{\left(\epsilon_{M} / \nu\right)^{m}}\right]_{\operatorname{Pr}}=\text { constant }
$$

The two constants, $A$ and $m$, in this equation must be evaluated trom expertmexial data. They can be evaluated from experimental determinations of elther $\psi$ or $\mathrm{h}$, the heat transfer coefficient.

There are available three sets of results on the experimental determination of 4 . which might be used to evaluate $A$ and $m$. They, shown in Figure 1, were all obtained with mercury, were based on measurement of velocity and temperature profiles, and were all supposed to be obtained under conditions of turbulent flow where both velocity and temperature profiles ware fully established. Isakoff and Drew (8) made their measurements in a 1.5 in. I.D. stainless steel electrically-heated round tube in the Peynolds number range 36,700 to 373,000 . Later Brown et al (7) made 
measurements in a 1.51 in. I.D. nickel stea m-heated round tube in the Reynolds number range 250,000 to 800,000 . And finally, Mizushina and Sesano (4). made measurements in a $25 \times 150 \mathrm{~mm}$ stainless steel rectangular channel in the reynolds number range 10,000 to 130,000 . The channel was heated on one side and cooled or the other by flowing water.

It is immediately apparent from Figure 1 that the agreement between the three sets of measurements is poor; but this is not coo surprising when one realizes how difficult it is to achieve high accuracy in making such measurements. The coordinates in Figure 1 were chosen for their pract1cal itility, as explined below.

Owing to the great differences which exist between the $i$ measurements of the different investigators, it was decided that it would be better to evaluate the constants in equation (20a) from h measurements, instead. For this, it is convenient to rewrite the equation as

$$
\bar{\psi}=\left[1-\frac{\mathrm{A}^{\prime}}{\left[\epsilon_{\mathrm{M}} / \nu\right]_{\max }^{\mathrm{m}}}\right]_{\mathrm{Pr}=\text { constant }}
$$

which correlates the average or effective value of the eddy diffusivity with the maximum value of $\epsilon_{M} / \nu$, the former being easier to use and the latter ${ }^{1}$

${ }^{1}$ The quantity $\left\{\epsilon_{N} / \nu\right]_{\text {av }}$ could also have been used. 
being easier to obtain. The quantity. $\bar{\psi}$ represents the average value of $\psi$ In the flow cross section for use in equations (28), (32), and (33). In this paper It was taken as equal to

$$
2 \int_{0}^{1} \psi(r / R) d(r / R)
$$

ior flow in cireular tubes.

Values of $\left[\epsilon_{M} / \nu\right]_{\max }$ used in this paper are shown plotted aga inst the Reynolds number in Mgure 2.

For flow in plpes, values of $\epsilon \mathrm{M}^{/ \nu}$ were calculated from the following equation, which is due to Deissler (2).

$$
\epsilon_{M} / \nu=0.72 s^{*}\left(1-\frac{y}{R}\right)(1-\sqrt{1-y / R})
$$

where $S^{m}=R / \nu \sqrt{\pi_{O}} / p$. The quantity $\epsilon_{M} / \nu$ reaches a maximum at about $y / R=0.6$.

For flow in annuli, $\epsilon_{M} / \nu$ was obtained by first calculating $\epsilon_{M}$ by use of the standard shear-stress equation

$$
\frac{\pi_{0}}{\rho}=\left[\frac{\mu}{\rho}+\epsilon_{M}\right] \frac{d u}{d r}
$$

The velocity distribution results of Rothfus ( 8 ) were used, and the method of calculation was the same as that used by Dwyer and $\mathrm{Tu}(9)$. Values of $\left[\epsilon_{M} / \nu\right]_{\max }$ were taken for that portion of the annulus lying between $r_{1}$ and 
$r_{m}$, because only the case of heat transfer to (or from) the inner wall of an annulus has been considered here. If heat transfer from the outer wall were considered, then $\left[\epsilon_{\mathrm{M}} / \nu\right]_{\max }$ should be for that portion of the annulus lying between $r_{m}$ and $r_{2}$.

For the case of in-line flow through rod bundles, $\epsilon_{M}$ was also calculated by means of equation (22), using the annulus-velocity-profile results of Rothfus and the method of Dwyer and Tu.

Referring to Figure 2 again, it will be noticed that, for the various geometries, there is a large spread in the values of $\left[\epsilon_{\mathrm{M}} / \nu\right]_{\max }$ for a given Reynolds number, with pipes giving the highest values and bundles the lowest. This means that for a given Reynolds or Peclet number, values of $\bar{\psi}$ a re greatest for flow in pipes and lea st for flow through bundles. Thus, in the latter case, considerable error can be introduced by assuming that 4 equals unity, as is often done for tlow in pipes, particularly at the lower peclet numbers. It is found that equation (20b) gives a type of $\bar{\psi}$ vs. $\left[\epsilon_{\mathrm{M}} / \nu\right]_{\max }$ curve similar to the dashed curve in Figure 3. Moreover, on the basis of a vallable heat transfer results for turbulent flow of liquid metals through pipes, annuli, and rod bundles, it is found that such a curve brings theory and experimental results into very good agreement. After evaluating the constants, equation $(20 \mathrm{~b})$ becomes 


$$
\bar{\psi}=1-\frac{91.0}{\left|\epsilon_{M} / \nu\right|_{\max }^{1.4}} \mathrm{Pr}=0.02
$$

for a Prandt! number of 0.02 .

Figure 3 presents a comparison of three theoretical equations for estimating the eddy diffusivity ratio. Jenkins' (1) method calls for solving the following two equations si multaneously:

$$
\begin{aligned}
& \frac{C M}{\left[v^{\prime}\right.}-\frac{f v^{\prime}}{v}+\frac{2}{15}-\frac{12}{\pi^{6}} \cdot \frac{l v^{\prime}}{v=\infty} \sum_{n=1}^{n=\infty} \frac{1}{n^{6}}\left(1-e^{\left.\left.-n^{2} \pi^{2} \nu / l v^{\prime}\right)\right]}\right. \\
& \psi=\operatorname{Pr} \frac{\frac{2}{15}-\frac{12}{6} \cdot \frac{f v^{\prime}}{\alpha} \sum_{n=1}^{n=\infty} \frac{1}{\pi^{6}}\left(1-e^{\left.-n^{2} \pi^{2} \alpha / l v^{\prime}\right)}\right.}{\frac{2}{15}-\frac{12}{8} \cdot \frac{l v^{\prime}}{\nu} \sum_{n=1}^{n=\infty} \frac{1}{\pi^{6}}\left(1-e^{-n^{2} \pi^{2} \nu / l v^{\prime}}\right.}
\end{aligned}
$$

In solving these equations to estimate $\vec{\psi}$, it was assumed that $\bar{\psi}=\psi$ at $y / P=0.2$ and that

$$
\left[\epsilon_{\mathrm{M}} / \nu\right]_{\mathrm{y} / \mathrm{R}}=0.2=\left.0.6\right|_{\mathrm{M}} /\left.\nu\right|_{\max }
$$

Both of these assumptions appear to be reasonably well borne out by the available facts. It is interesting to note that equations (23) and (24) have no constants which have been evaluated from experimental data. 
Azer and Chao (3) have proposed the equation

$$
\psi=\frac{1+135 \operatorname{Re}^{-0.45} \exp \left[-(y / R)^{0.25}\right]}{1+380 \mathrm{Pe}^{-0.58} \exp \left[-(y / R)^{0.25}\right]}
$$

tor estimating values of $\psi$. Here again $\bar{\psi}$ was assumed equal to $\psi$ at $y / R=$ 0.2. The constants in this equation are based on eddy diffusivity measurements made on turbulent flow of air in pipes by Sleicher (10). Equation (26) is represented by curve B in Figure 3.

Finally, Mizushina and Sasano (4), based upon their experimental studies described above, have proposed the following equation:

$$
\psi=0 .: 63\left(\epsilon_{\mathrm{M}} / \nu\right) \operatorname{Pr}\left[1-\exp \frac{-1}{0.242\left(\epsilon_{\mathrm{M}} / \nu\right)^{\mathrm{Pr}}}\right]
$$

For Figure $3, \bar{\psi}$ was assumed e jual to 0.94 at $\left[\epsilon_{M} / \nu\right]_{\max }$, which appears to be generally true, based on the results of Brown et al (7) and Azer and Chao (3) for flow inside pipes. In any case, the uncertainty of the location of curve $A$ in the figure is very small compared to the differences between It and the other curves.

Curves $B$ and $C$ are in surprisingly close agreement, but they are both tar from curve A and the now-proposed dashed curve. In tact, all three theoretical curves would obviously fail to reconcile theoretical predictions and supposedly dependable experimental results in liquid-metal hest transfer. 
Equation $(20 \mathrm{c})$ is shown plotted in Figure 4. For a given Peclet number, it appears that $\bar{\psi}$ is independert of $\mathrm{Pr}$ in the fully turbulent regime where $\bar{\psi} \geqslant 0$. This is tanta mount to saying that the constant $\mathrm{c}$ in equation (20) is negligible compared to the a/Pr term. Under these conditions, the equation becomes

$$
\bar{\psi}=1-\frac{1.82}{\operatorname{Pr}\left[\epsilon_{M} / \nu\right]_{\max }^{1.4}}
$$

which was then used to calculate the curves for $\mathrm{Pr}_{\mathrm{r}}=0.01$ and 0.03 in Figure 4.

Values of the parameter $\bar{\psi}$, evaluated by equation (20d) will now be used to predict new Nu vs. Pe curves for turbulent flow of li quid metals through circular tubes, concentric annuli, and rod bundles. These curves will then be compared with available experimental results.

Care was exercised in choosing experimental results for comparison whit the new theoretical curves. No results published prior to 1956 were used. Before that date, results were for the most part obtained on mercury and lead-bismuth alloy, under conditions where "wetting" probably did not exist. This meant that entra ined gas and/or particulate matter, which are often present, probaibly collected at the interface between the flowing metal and heated surface, cont ributing to low results. Results 
obtained in recent years, under Improved experimental conditions, tend to give higher coefficlents, particularly at the higher "eclet n"imbers.

In the comparisons below, the experimental results which are used were obtained, for the most part, under wetting conditions or where rela tively high contact resistances were not suspected.

\section{FLOW IN CIRCULAR TUBES}

The standard semi-theoretical, semi-empirical equation for this case is the so-called Lyon-Martinelli (11) equation,

$$
\mathrm{Nu}=7.0+0.025(\bar{\psi} \mathrm{Pe})^{0.8}
$$

in which the parameter $\bar{\psi}$ is often taken as unity at all values of the Peclet number. Combining this equation with (20d) gives

$$
\mathrm{Nu}=7.0+0.025 \mathrm{Pe}-\frac{1.82 \mathrm{Re}}{\left(\epsilon_{\mathrm{M}} / \nu\right)_{\max }^{1.4}}{ }^{0.8}
$$

which will now be tested against experimental results.

Equation (29) applies when the Peciet number is in excess of 400.

High Peclet Number Range

Figure 5 shows the experimental results of Brown et al (7) and KIrillov et al (12), both for mercury flowing in nickel tubes. For this case, particula rly in this range of Peclet numbers, there is little difference between equations (28) and (29). Nevertheless, equation (29) appears to fit the data 
points better. The two sets of experimental results are in good agreement. The Hg-Ni system is a "wetting" system. Therefore, there should have been no contact resistances to heat transfer between solid and liquid metals. Intermedlate Peclet Number Range

In this range, three sets of experimental data are avallable for comparison with equations (28) and (29). Please refer to Figure 6. Due to lack of agreement between the resuits of the different investigators, a clearcut comparison between theory and experiment is not possible. However, the curve for equation (29) seems to represent a compromise between the differing results. The results of Kirillov et al (12) are believed to be too high. It is difficult to see, for example, how in the Peclet number range 400 to 1000 their results could be consistent with the idea that $\bar{\psi}$, in that range, is equal to unity. On the other hand, the results of Novikov et al (14) would appear to be too low. In each of the three sets of data, the soltd-liquid metal system was such as to expect "wetting" to exist.

\section{Low Peclet Number Range}

Calculated Nusselt numbers from equations (28) and (29) will now be compared with the limited experimental results avallable. In the low Peclet number range, two sets of experi mental results are compared with the theoretical curves; but here again, as seen in Figure 7, wide disagreement 
exists between the experimental results. Pirogov's (15) results are clearly too high, for in the stream-line region they fall about $40 \%$ above the correct Ine. On the other hand, the results of Petukhov and Yushin (16), while correct in the stream-line region, fall lower and lower as the flow gets more and more into the turbulent region. One possible explanation of these results is that, In all probability, "wetting" did not exist and consequently an appreciable contact resistance may have been present, which would have tended to reveal itself more as the flow rate increased.

Again, the presently-proposed curves represent a compromise between the conflicting experimental results. Comparison of Different Equations for $\psi$

Referring to Figure 3 again, it will be seen that the equation of Mizushina and Sasano, of the three represented there, comes the closest to the required relationshlp between $\bar{\psi}$ and $\left[\epsilon_{\mathrm{M}} / \nu\right]_{\max }$ as represented by the dashed curve. For that reason, values of $\bar{\psi}$ calculated by that equation were used to solve equation (28) to see how the Nusselt numbers would compare with those calculated from equation (29). The resuits are shown in Figure 8. Values of $\bar{\psi}$ by the equation of Mizushina and Sasano give results which, over most of the Peclet number range, are quite low. At the very high Peclet numbers, however, they fall above the Lyon-Martinelll curve, and to an unexpectedly high degree. 
There is another semi-empirical equation for estimating values of $\overline{4}$ which has not been discussed thus tar, and that is the equation of Delssler (2), 1.e.

$$
\bar{\psi}=\mathrm{B}(\mathrm{Pe})\left[1-\mathrm{e}^{-1 / \mathrm{B}(\mathrm{Pe})}\right]
$$

This equation was not plotted in Figure 3, because its constant. B, has to be determined by arbitrarily setting $\bar{\psi}$ at some particular value for a given value of the Peclet number. The other equations plotted in Figure 3 did not have this restriction. To see how well equation (30) compared with equa tion (20d). B was evaluated at a point on the curve of equation (20d) which would produce the best agreement between the two. The result is also shown in Figure 8.

When evaluating $\vec{\psi}$ by Deissler's equation, the reduction of the Nusselt number from the Lyon-Martinelli equation varies from about one-half to twice that obtained when evaluating $\bar{y}$ by equation (20d).

Moreover, both the equation of Mizushina and Sasano and that of Delssler for evaluating $\bar{\psi}$ produce curves, which, at the lower end of the turbulent regime, come far from merging with the Nu vs. Pe line for streamline flow. Finaliy, these two equations for evaluating $\bar{\psi}$ would show even wider discrepancles for the cases of flow through annull and rod bundles; 
for, as mentioned earlier, the differences in the Nusselt number between taking $\bar{\psi}$ equal to one and evaluating it properly are much greater in these cases than for the case of flow in pipes.

The equations of Jenkins (1) and Azer and Chao (3), if used to calculate $\bar{\psi}$, would give Nu vs. Pe curves which would fall much lower than the other curves in Figure 8.

Recommended Cir ves

Figure 3 shows the suggested curves for representing heat transfer conditions in the transition region and in the lower portion of the turbulent reglon. Curve $A B$ represents equation (29). At point $B$, which corresponds roughly to the point in Figure 3 where the dashed curve intercepts the abscissi, curve AB branches into a family of curves with Prandtl number as parameter. These curves, in turn, terminate at the viscous-flow line represented by the equation

$$
\mathrm{Nu}=48 / 11
$$

Finally, curves $A B C, A B D, A B E$, and $A B F$ represent heat transfer rates for liquid metals having Prandtl numbers $0.005,0.01,0.02$, and 0.03 , respectively. These curves were simply drawn in by suitably connecting their established terminal points. 


\section{FLOW IN CONCENTRIC ANNULI}

Heat transfer to liquid metals flowing under conditions of constant heat flux, fully-established turbulent flow, and heat transfer through the inner wall only, is represented by the following semi-empirical equation of Dwyer and Tu (17).

$$
\mathrm{Nu}=\alpha_{1}+\beta_{1}(\bar{\psi} \mathrm{Pe})^{\gamma_{1}}
$$

where

$$
\begin{aligned}
& \alpha_{1}=4.63+0.386 y \\
& \beta_{1}=0.02154-0.000043 y
\end{aligned}
$$

and

$$
\gamma_{1}=0.752+0.01657 y-0.000883 y^{2}
$$

This equation with $\bar{\psi}$ taken as unity corresponds to the Lyot -Martinelli equation for flow inside circular tubes. It will now be compared with experimental results both ways, i.e., where $\bar{\psi}$ is taken as unity and where it is evaluated by equation (20d). Figure 10 shows the results of Subbotin et a! (18) for flow of mercury through an annulus having a y value of 1.09 , whtch closely approximates the geometry of parallel plates. And Figure 11 shows the results of Petrovichev (19) for flow of mercury through annult having y values of 1.55 and 1.67 . These $y$ values are sufficiently close together to be represented by a single theoretical curve. In both of these figures it is seen that 
equation (32) with $\bar{\psi}$ evaluated according to equation (20d) represents the experimental results decidedly better than if $\bar{\psi}$ were taken as unity at all values of the Peclet number.

\section{IN-LINE FLOW THROUGH ROD BUNDLES}

Dwyer and $\mathrm{Tu}(9)$ have recommended the following semi-empirical equation for this case.

$$
{ }_{N}^{N u}=0.93+10.81 \frac{P}{D}-2.01(P / D)^{2}+0.0252(P / D)^{0.273}(\vec{\psi} P e)^{0.8} .
$$

It is based on the conditions of fuliy-established turbulent flow, constant heat flux, and equilateral triangular pitch. Following the same procedure as before equation $(3 j)$ is plotted in Figure 12 two ways: with $\bar{\psi}$ assumed equal to unity and with $\vec{\psi}$ evaluated according to equation (20d). The agreement between the former curve and the experimental results of Friedland et al (20) is very poor. whereas that between the latter curve and the experimentai results is excellent. The experimental points shown in Figare 12 a re the same as those given in Figure 5 of reference (20). except that slight cor rections for variation in heat loss from the test section have been applied. The results were obtained on the central rod of a 13-rod bundle. It was chromium-plated and therefore unwetted by the mercury. The results shown are belleved to be reliable for they have since been duplicated 
several times (21) by results on other elements, both wetted and unwetted, at the Brookhaven National Laboratory.

It will be noticed that the difference between the two curves in Figure 12 is quite large compared to the difference between the two curves in Figure 5, for example. This is due to the fact that, at a given Reynolds number, the value of $\left[\epsilon_{M} / \nu\right]_{\max }$ is much less for flow through rod bundles than for flow through pipes. This leads to a situation in the lower portion of the turbulent flow regime which is of considerable interest, as tar as heat transfer to liquid metals flowing in-line through rod bundles is concerned.

Figure 13 presents what the author believes to be the situation for heat transfer to rod burd les, covering the whole flow spectrum, from streamline flow to very turbulent flow. Three curves are shown, each for a differ ent $P / D$ ratio. The interesting thing is that the Nusselt number, for a given $P / D$ ratio, remains essentlally constant at the strea $m$-line value for a long distance into the turbulent regime, indicating that in this region the eddy contribution to heat transfer is negligible. As the flow rate is increased, a point is reached where eddy transfer begins rapidly to assert itself, and soon thereafter the Nusselt number increases a imost proportionately with the 0.5 power of the Peclet number. 
It will be noticed that, in the case of flow in tubes, the Nusselt number begins to rise above the strea $\mathrm{m}$-line value as soon as the flow hecomes turbulent: whereas in the case of in-line flow through bundies, the Nusselt number does not rise above the stream-line value until a Reynolds number of about 25000 (for $\mathrm{Pr}=0.02$ ) is reached. Again, the reason for this is found in Figure 1, 1.e., for a given Reynolds number, values of $\epsilon \mathrm{M}^{/ \nu}$ for pipes are about a factor of four greater than those for bundles. In other words, for bundles, below $\mathrm{Re}=25000$, the eddies do not travel tast enough to prevent losing essent lally all their sensible heat while in transit.

\section{ALTERNATIVE EQUATIONS FOR $\bar{\psi}$}

By making somewhat different assumptions, it is possible to derive a number of equations, besides (20) and $(20 \mathrm{a})$, for evaluating the quantity 4 , all based upon the basic idea used in deriving equation (20).

For example, if the $\left(\epsilon_{M} / \nu\right)^{n}$ term is omitted from equations (6) and (9) which ts simply to assume that the heat and momentum undelivered by the eddy particle is proportional to the heat and momentum, respectively, lost by a representative single particle in transit, then we get

$$
\downarrow=1-\frac{(a \text { constant })+\frac{a \text { constant }}{\mathrm{Pr}}}{\epsilon_{\mathrm{M}} / \nu}
$$

which is the same as equation (20), except there is no exponent on the $\mathcal{E}_{M} / \nu$ term. 
Again, if in deriving equation (34), we had assumed that $\epsilon_{M}$ is proportional to bv', we would have obtained the equation

$$
\psi=\frac{1-\frac{\text { a constant }}{\operatorname{Pr}\left(\epsilon_{M} / \nu\right)}}{1-\frac{\text { a constant }}{\epsilon_{M} / \nu}}
$$

If we had assumed a model where the flow was turbulent rather than strea $\mathrm{m}$-line, instead of equation (8) for $\mathrm{h}$ and (15) tor $\mathrm{F}$, we would have to use their turbulent counterparts. For h, we can use the following equation, proposed by Ranz ani Marshall (22)

$$
\frac{{ }_{0}{ }_{0}}{k}=2.0+0.8\left(d_{0} v^{\prime} / v^{1 / 2}\left(C_{p}{ }^{11 / k^{1 / 3}}\right)^{1 / 3}\right.
$$

and for $F$, the equation would be

$$
F=\frac{\left(a \text { constant } \rho_{\rho}\left(v^{\prime}\right)^{2} d_{0}{ }^{2}\right.}{g_{0}}
$$

Using these equations, and the same general procedure employed in deriving equation (20), a comparable relationship for $\psi$, on the basis of a turbulent modei, can be obtained. Thts relationship, however, is complex. It can be simplified by making assumptions similar to those made in obtaining equations ( 4 ) and (35). For example, if it is assumed that the particle Reynolds number is proportional to $\varsigma_{M} / \nu$, one obtains 


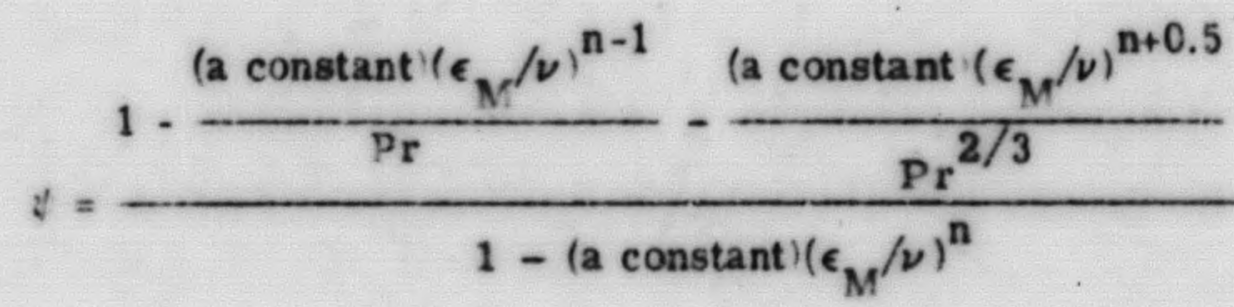

This equation, having four constants, could be made to fit almost any curve. and therefore it does not prove very much. Making the further simplify ing assumption of dropping the $\left(\epsilon_{\mathrm{M}} / \nu\right)^{\mathrm{n}}$ term from equation (6), as was done to obtain equation (34), we end up with

$$
\downarrow=(a \text { constant })-\frac{\left(a \text { constant }-\left(a \text { constant } \mid \mathrm{Pr}^{1 / 2}\left[\epsilon_{\mathrm{M}} / \nu\right)^{1 / 3}\right.\right.}{\operatorname{Pr}\left[\epsilon_{\mathrm{M}} / \nu\right]}
$$

It was subsequently found that the first constant In this equation was so close to unity that it was set at that, the two constants in the numerator then being evaluated from experimental data. 
Equation (34) actually has two constants, but one of them was dropped as was done in equation (20). This was done for two reasons: first, there are not sufficient experimental results avallable for different values of the Prandtl number to evaluate the second constant, and second, this constant is most probably negligible compared to the other tern in the numerator of the fraction. This latter assumption is consistent with the idea that in the higher part of the Peclet number range the Nusselt number is independent of Prandtl number, for liquild me tals.

The constants for equations (34), (35), and (39) were evaluated from the dashed curve in Figure 3, the final equations becoming

$$
\begin{aligned}
& \vec{\psi}=1-\frac{0.36}{\operatorname{Pr}\left[\epsilon_{M} / \nu\right]_{\max }} \\
& \vec{\psi}=\frac{1-\frac{0.524}{\operatorname{Pr}\left[\epsilon_{M} / \nu\right]_{\max }}}{1-\frac{12.75}{\left.\mid \epsilon_{M} / \nu\right]_{\max }}}
\end{aligned}
$$

and

$$
\bar{\psi}=1-\frac{0.700 \cdot 0.157 \mathrm{Pr}^{1 / 2}\left[\cdot \epsilon_{y} /\left.\nu\right|_{\max } ^{1 / 3}\right.}{\operatorname{Pr}\left[\epsilon_{M} / \nu\right]_{\max }}
$$


As before, $\bar{\psi}$ and $\left[\epsilon_{M} / \nu\right]_{\max }$ were used instead of $\psi$ and $\epsilon_{M} / \nu$, when determining the constants. The three equations are plotted in Figures 14, 15, and 16 , respectively.

The striking similarity of the curves for these three equations, as well as those for equation (20d) shown in Figure 4, is Immediately apparent. This is so, even for equation (34a) which has only a single constant. The similarity of these equations, as tar as their curves are concerned. shows that any of them could be used to evaluate $\bar{\psi}$, without causing much displacement in the final Nu vs. Pe curves; which tends to give added support to the theoretical approach which has been used.

Another point ts worthy of mention. The spacings of the three curves In Figures 15 and 16 are such that they indicate the Nusselt number to be Independent of the Peclet number in the higher Peclet number range. This was, In part, the fustification for dropping one of the two constants in equa tions (20) and (34).

Equation (39a). with respect to the other three equations, is unique in that it gives values of $\bar{\psi}$ which can exceed unity, but only slightly. There Is no theoretical reason why $\bar{\psi}$ cannot exceed unity. In tact, this author sus pects that it may well do so, at very high Reynolds numbers. This then raises a question concerning the assumption of strea m-line flow conditions 
at the boundary layers surrounding the individual eddy particles, which was made in deriving equation (20). It may well be that this assumption is not entirely valid at very high degrees of turbulence. If so, an equa tion such as (20d) would be the one to use in the lower portion of the turbulent regime, and one such as ( $39 \mathrm{a})$ in the upper portion.

In Ilquid metal heat transfer, as the flow rate is increased, a point ts reached where essentially all of the heat in convective transter would be transterred by eddy transport, as is the case with ordinary fluids in the turbulent flow regime. Since values of $\bar{\psi}$ for such flulds appear to be slightly above unity at high flow rates, there is reason to expect that $\bar{\psi}$ values for liquid metals would also be slightly above unity. However, the departures from unity would be small and therefore have little effect on the Nu vs. Pe curve. Before such tine distinctions are possible, more experimental results of high accuracy are required.

\section{CONCLUSIONS}

Based upon the present study, the following are recommended for estimating heat transfer rates for liquid metals flowing under conditions where the beat flux is constant and the flow is turbulent and fully establlshed. 
Flow in circular tubes:

$$
\begin{aligned}
& \text { Above } \mathrm{Pe}=400, \text { equation (28) [Lyon-Martinelli (11)]. } \\
& \text { Below } \mathrm{Pe}=400, \text { see Figure } 9 .
\end{aligned}
$$

Flow in concent ric annult (heat transfer from tnner wall only):

$$
\text { Above } \mathrm{Pe}=400 \text {, Equation (32) \{Dwyer and Tu (17) }\} \text {. }
$$

Flow through rod bundles (equilateral triangular spacing, and not closely packed:

$$
\begin{aligned}
& \text { Above } \mathrm{Pe}=1000, \text { Equation (33) [Nwyer and } \mathrm{Tu}(9)\} . \\
& \text { Below } \mathrm{Pe}=1000, \text { see Figure } 13 .
\end{aligned}
$$

In each of the above equations, i should be evaluated by equation (20d). values of $\left\{\epsilon_{\mathrm{M}} / \nu\right\}_{\max }$ for the various geometries being given in Figure 2. For circular tubes, equation (29) combines equations (20d) and (28).

The fact that $i$, for use in equations (28), (32), and (33), can -be evaluated by a single relationship is taken as an indication of its funda mental soundness.

The constants in equations (20d), (34a), (35a), and ( $39 a)$ have been evaluated with the most dependable experimental results available at this time. As additional and more accurate results become avallable, these constants can be expected to change. However, they can change considerably, as seen by comparing equations ( $20 \mathrm{~d}$ ) and ( $34 \mathrm{a}$ ), without greatly affecting the final results, as seen by comparing Figures 4 and 14 . 


\section{NOTATION}

$a=a$ constant in Eq. (11)

$A=a$ constant in Eq. (20a)

$A^{\prime}=$ a constant in $\mathrm{Eq} .(20 \mathrm{~b})$

$\mathrm{b}=$ effect:ve $\mathrm{fllm}$ thickness around eddy particle, $\mathrm{ft}$

$B=a$ constant in Eq. ( 30$)$

$c=a$ constant in Eq. (19)

$C_{p}=$ specific heat, Btu/(lb-mass $)\left({ }^{\circ} \mathrm{F}\right)$

$t_{0}=$ Glameter of eddy particle, it

$D$ = outside diameter of rod or tube, ft

$D_{e}=4($ cross -sectional flow area $) /$ wetted perimeter, $\mathrm{ft}$

$t_{H}=$ traction of heat energy, originally possessed by an eddy particle, which is delivered at point where particle comes to rest with respect to rest of fluid

$\mathrm{f}_{\mathrm{M}}=$ same as $\mathrm{f}_{\mathrm{H}}$ except for momentum transfer

$F$ : drag force on eddy particle. Ib force

$\mathrm{g}_{\mathrm{o}}=$ conversion tactor, (lb-mass)(ft)/(tb-force)(hr)$)^{2}$

h * heat transfer coefticlent, Btu/(hr) $\left.(\mathrm{ft})^{3}{ }^{\circ} \mathrm{F}\right)$

$\mathbf{k}$ : thermal conductivity, Btu $/(\mathrm{hr})(\mathrm{ft})\left({ }^{\circ} \mathrm{F}\right)$

$f=$ eddy mixing length, delined by Eq. (1), ft

$\mathrm{m}=$ exponent in Eq. (20) 
$\mathrm{n}=$ exponent in Eq. (6)

$\mathrm{Nu}=\mathrm{hD} / \mathrm{k}=$ Nusselt number, dimenstioniess

$\mathrm{Nu}_{1}=$ Nusselt number for heat transfer to liquid metals flowing

through concentric annull, where heat is transterred from

the inner wall only, dimensionless

$P=$ rod pitch, or distance between rod centers in bundle, $f t$

$\mathrm{Pe}=\frac{\mathrm{D}_{\mathrm{e}} \mathrm{v}_{\mathrm{av}} \rho \mathrm{C}_{\mathrm{p}}}{\mathrm{k}}=$ Peclet number, dimensionless

$\mathrm{Pr}=\mathrm{C}_{\mathrm{p}} \mu / \mathrm{k}=$ Prandtl number, dimensionless

$q=$ heat flux, Btu/(hr)(ft $)^{2}$

$r=$ radius, $f t$

$r_{1}=$ inner radius of concentric annulus, $\mathrm{ft}$

$r_{2}=$ outer radius of concentric annulus, $f t$

$r_{m}=$ radius of maximum velocity in concentric annulus, $f$

$R=$ radius of circular tube, $f t$

$R_{e}=\frac{D_{e}{ }_{a} \rho}{\mu}=$ Reynolds number, di mensionless

$S^{*}=(\dot{r} / \nu)(\mathrm{R} / \rho)^{1 / 2}=$ tube -radius para meter, dimensionless

$\mathbf{t}=$ temperature, ${ }^{\circ} \mathbf{F}$

$t_{e}=$ temperature of eddy particle, ${ }^{\circ} \mathrm{F}$ 
$\mathrm{u}=$ linea $r$ velocity at radius $r$ in $x$ direction, $\mathrm{ft} / \mathrm{hr}$

$u^{\prime}$ = measure of turbulence tntensity, or root mean square of differ-

ence between particle velocity and that of the rest of the fluid, In the $x$ direction, $\mathrm{ft} / \mathrm{hr}$

$v^{\prime}=$ same as $u^{\prime}$ except in y direction, $\mathrm{ft} / \mathrm{hr}$

$\mathrm{v}_{\mathrm{av}}=$ average linear velocity through pipe, annulus, or rod bundle,

$\mathrm{ft} / \mathrm{hr}$

$\mathrm{x}=$ axial distance, $\mathrm{ft}$

$y=$ radial distance measured from tube wall, $\boldsymbol{f t}$. Also with reference to concentric annuli, y $-\mathrm{r}_{2} / \mathrm{r}_{1}$ dimensionless

\section{Greek Letters}

$\alpha_{1}, \beta_{1}, \gamma_{1}=$ quantities defined in Eq. (32) dimenisionless

$\epsilon_{\mathrm{H}}=$ eddy diffusivity for heat transfer, $\mathrm{tt}^{2} / \mathrm{hr}$

$\epsilon_{M}=$ eddy difiusivity for momentum transfer, $t^{2} / \mathrm{hr}$

$u=$ viscosity, $1 \mathrm{~b}$-mass $/(\mathrm{ft})(\mathrm{hr})$

$\nu=$ kinematic viscosity, $\mathrm{ft}^{2} / \mathrm{hr}$

$\rho=$ density, $\mathrm{lb}$-inass $/ \mathrm{ft}^{3}$

$\tau=$ shear stress at radius $r, \mathrm{lb}-\mathrm{force} / \mathrm{ft}^{2}$

$\psi=\epsilon_{\mathrm{H}} / \epsilon_{\mathrm{M}}$, dimensionless

$\bar{\psi}=$ average va lue of $\psi$ for use in Eqs. (28), (32), and (33), dimensionless 


\section{LITERATURE CITED}

1. Jenkins, R. "Heat Transter and Fluid Mechanics Institute," Stanford, California, p. 147, Stanford University Press (1951).

2. Deissler, R. G. "Analysis of Fuliy Developed Turbulent Heat Transfer at Low peclet Numbers in Smooth Tubes with Application to Liquid Metals," Nat. Advisory Comm. Aeronaut., Research Memo E52 F05, Washtington, 1852.

3. Azer. N. Z., and B. T. Chao, International Journal of Heat and Mass Transfer 1, No. 2/3, 121 (1960).

4. Mizushina, T. and T. Sasano, "The Ratio of the Eddy Diffusivities for Heat and Mounentum and its Effect on Liquid Metai Heat Transter Coefficients," Paper No. 78, presented at the 1961 International Heat Transter Conference, Boulder, Colo., and London, England: Proceedings will be published by A.S.M.E.

5. Prandtl, L., Z. Angew. Math. u. Mech. 5, 136 (1925).

6. Isakoff, S. E., and T. B. Drew "Proceedings of the General Discussion on Heat Transfer," London Conference, I.M.E. and A.S. M.E., p. 405 (1951).

7. Brown, H. E., B. H. Armstead, and B. E. Short, Trans. A.S.M. E. 79, No. 2, 279 (1957).

8. Rothlus, R. R., J. E. Walker, and G. A. Whan, A. I. Ch. E. Journal 4 , No. 2, 240 (1958). 
9. Dwyer, O. E. and P. S. Tu, Chem. Eng. Progr. Symposium Series 56, No. $30.183(1960)$.

10. Sleicher, C. A. Trans. A.S.M. . $80,693(1258)$.

11. Lyon, R. N., Chem. Eng. Progr. 47, 75 (1951).

12. Kirillov, P. L., et al., Soviet Journal of Atomie Energy 6, No. 4, 253 (1960).

13. Khabakhpseheva, E. M., and Y. M. II'in, Atomnaya Energiya 8, 494 (1960).

14. Novikov, I. I., et al., Atomnaya Energiya, Vol. 1, No. 4, p. 92 (1956).

15. Pirogov, M. S., Atomnaya Energlya 8, No. 4, 367 (1960).

16. Petukhov, B. S., and A. Y. Yushtn, Soviet Physics - Doklady 6 , No. 2 . 159 (1981).

17. Dwyer, O. E., and P. S. Tu, "Unilateral Heat Transfer to Liquid Metals Flowing in Concentric Annuli," submitted to Nu clear Sci. and Eng. tor publieation from Brookhaven Naticnal Laboratory.

18. Subbotin, V. I., et al., Alomnaya Energiya 8, No. 4, 310 (1960).

19. Petrovichev, v. I., Atomnaya Energiya ?, No. 4, 366 (1959).

20. Frledtand, A. J., et al., "Heat Transfer to Mercury In Parallel Flow through Bundles of Circular Rods," Paper No. 62, presented at the 1961 International Heat Transfer Conference, Boulder, Colo., and London, England. Proceedings will be published by A.S.M.E. 
21. Maresra, M. W., and O. E. Dwyer, "Heat Transfer to Mercury in Parallel Flow through Bundles of Circular Rods," paper to be published trom the Brookhaven National Laboratory.

23. Ranz, W. E., and W. R. Marshall, Jr., Chem. Eng. Progr., 48, No. 3.141 (1952). 


\section{FIGURE CAPTIONS}

Figure 2 Values of $\left[\epsilon_{\mathrm{M}} / \nu\right]_{\max }$ for fully-established turbulent flow of liquid metals through circular tubes, concentric annuli, and rod bundles with equilateral triangular spacing.

Figure 1 Comparison of the results of the experimental determination of the eddy diffusivity ratio hy various investigators, showing the effect of turbulence on $\bar{\psi}$.

Figure 3 Comparisons of thr uretical equations for estimating the eddy diffusivity ratio for liquid metals.

Figure 4 Graphical representation of Equation (20d).

Figure 5 Heat transfer to mercury flowing in round tubes in the high Peclet number range, under condition of constant heat flux. Compe.rison between semi-emplrical equations snd experimental results.

Figure 6 Heat transfer to liquid metals flowing in round tubes in the intermediate-Peclet-number range under condition of constant heat flux. Comparison between semi-empirical equations and experimental results.

Figure 7 Heat transter to liquid metals flowing in round tubes in the low-Peclet-number range under condition of constant heat flux. 
(cont.) Comparison between semi-empirical equations and experimental results.

Flgure 8 Comparison of semi-empirical equations for predicting heat transfer rates to liquid metals flowing in circular tubes under eonditions of constant heat flux and fully-established flow.

Figure 9 Recommended curves for predicting heat transfer rates to liquid metals flowing in ctrcular tubes under condit tons of constant heat flux and fully-established flow.

Figure 10 Heat transfer rates to mercury flowing in a concentric annulus under conditions of constant heat flux and heat transfer thruugh inner wall only. Compartson between semi-emplrical equations and experimental results of Subbotin et al. (18).

Figure 11 Heat transfer rates to mercury flowing in concentric annull under conditions of constant heat flux and heat transfer through inner wall only. Comparison between semt-empirical equations and experimental results of Petrovichev (19).

Figure 12 Heat transfer to mercury flowing in-line through unbaffled rod bundle under conditions of constant heat flux and fully-established now. Comparison between semi-empirical equations and experimental results of Friedland et al. (20) for mercury. 
Figure 13 Recommended curves for predicting heat transfer ratee to liquid metals flowing in-line through unbaftled cod bundles under constant heat flux and fully-established flow.

Figure 14 Graphical representation of Equation (34a).

Figure 15 Graphical representation of Equation (35a).

Figure 16 Graphleal representation of Fquation (39a). 


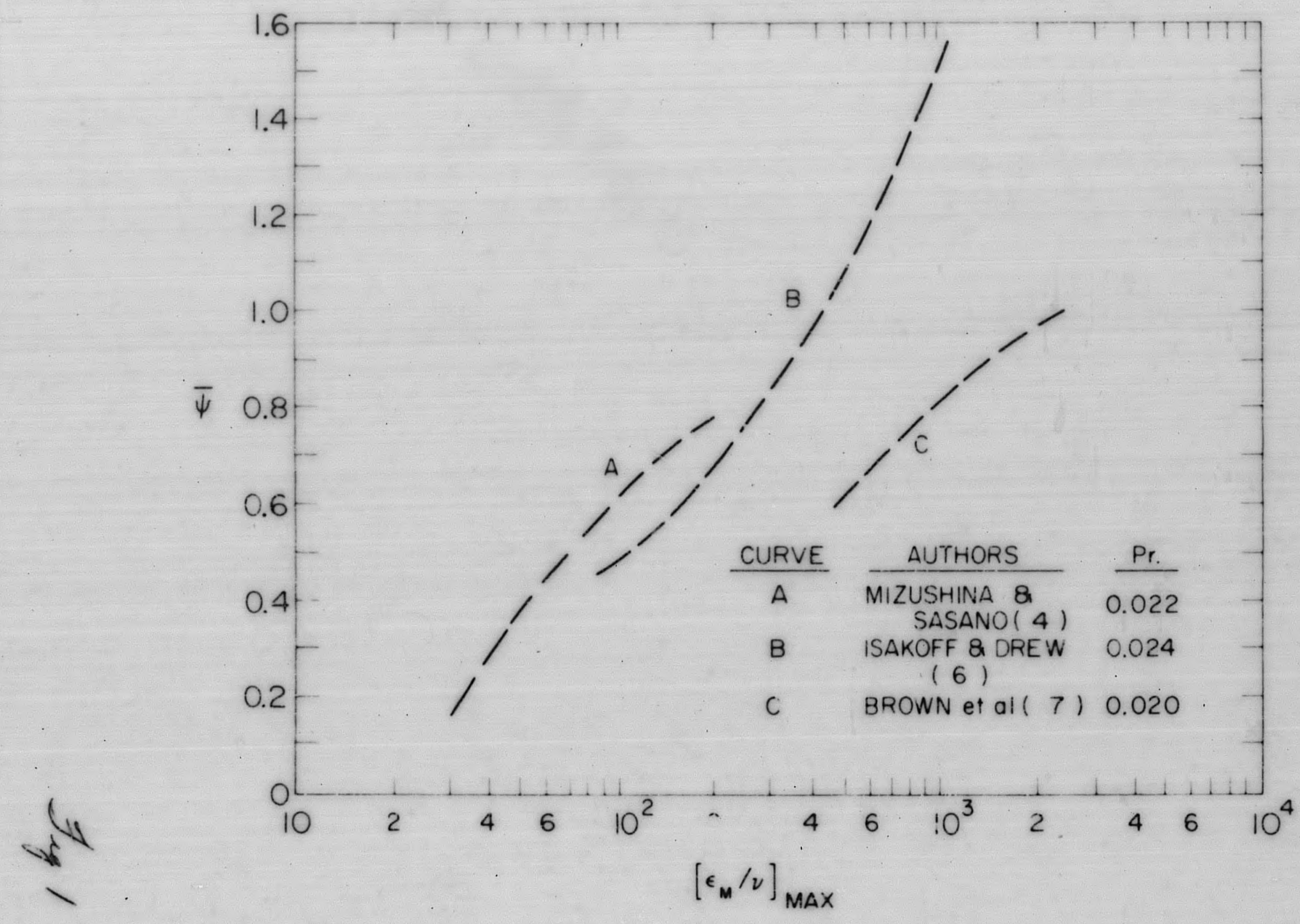

BNL NEQ No $3-341-62$ 


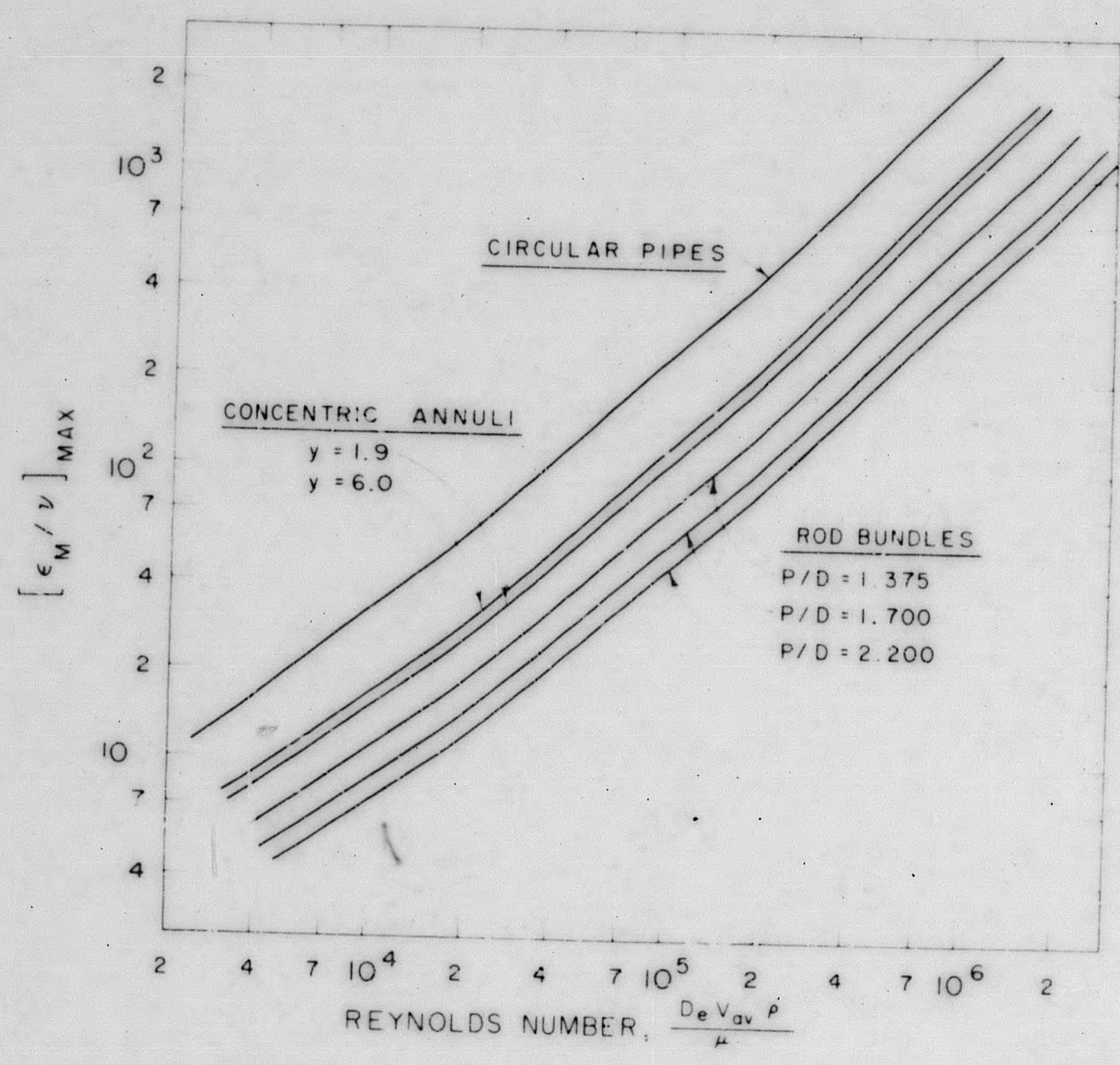

FNL NEP No 3-32?-60. 


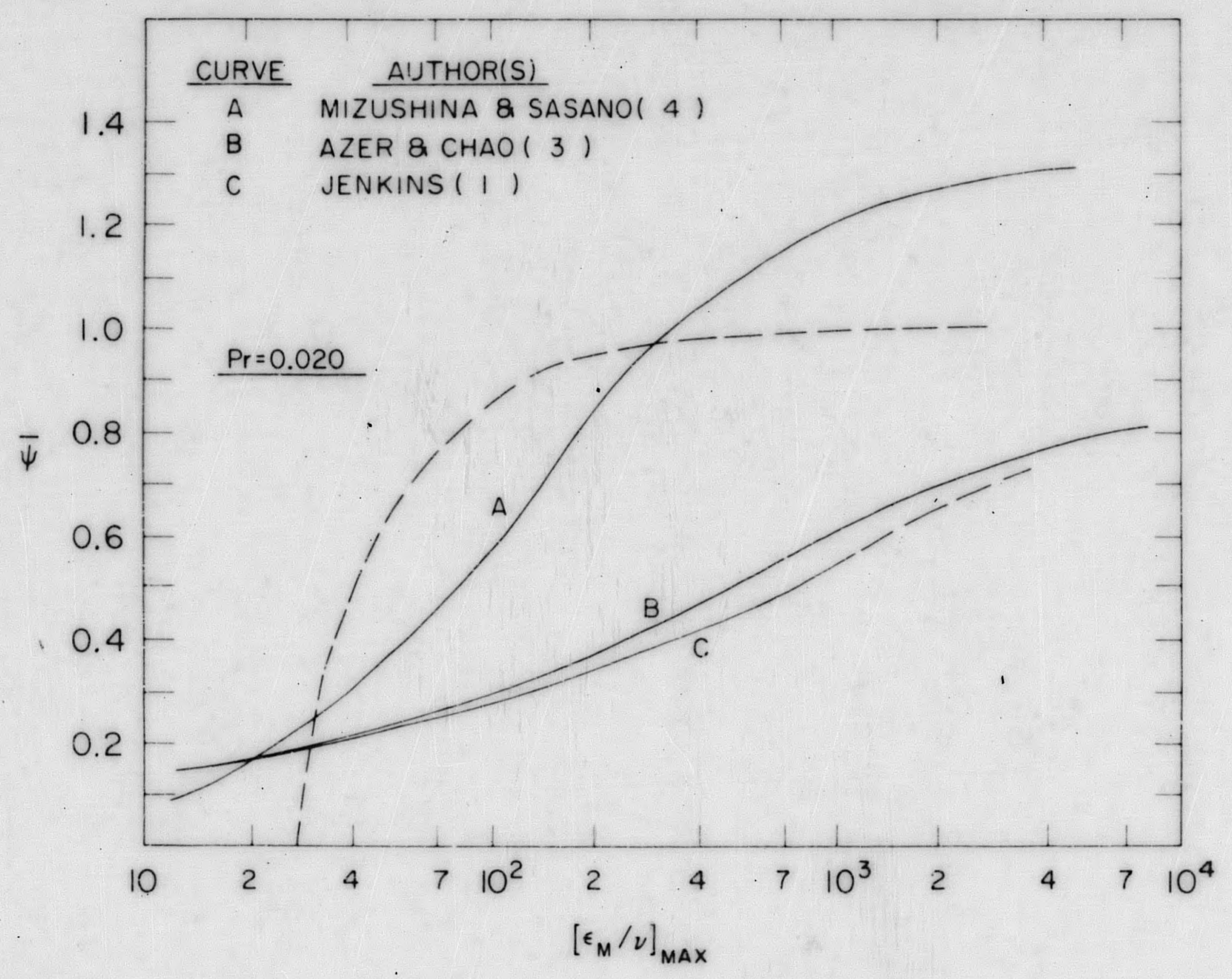

BNL NE9 No 3-328-62 


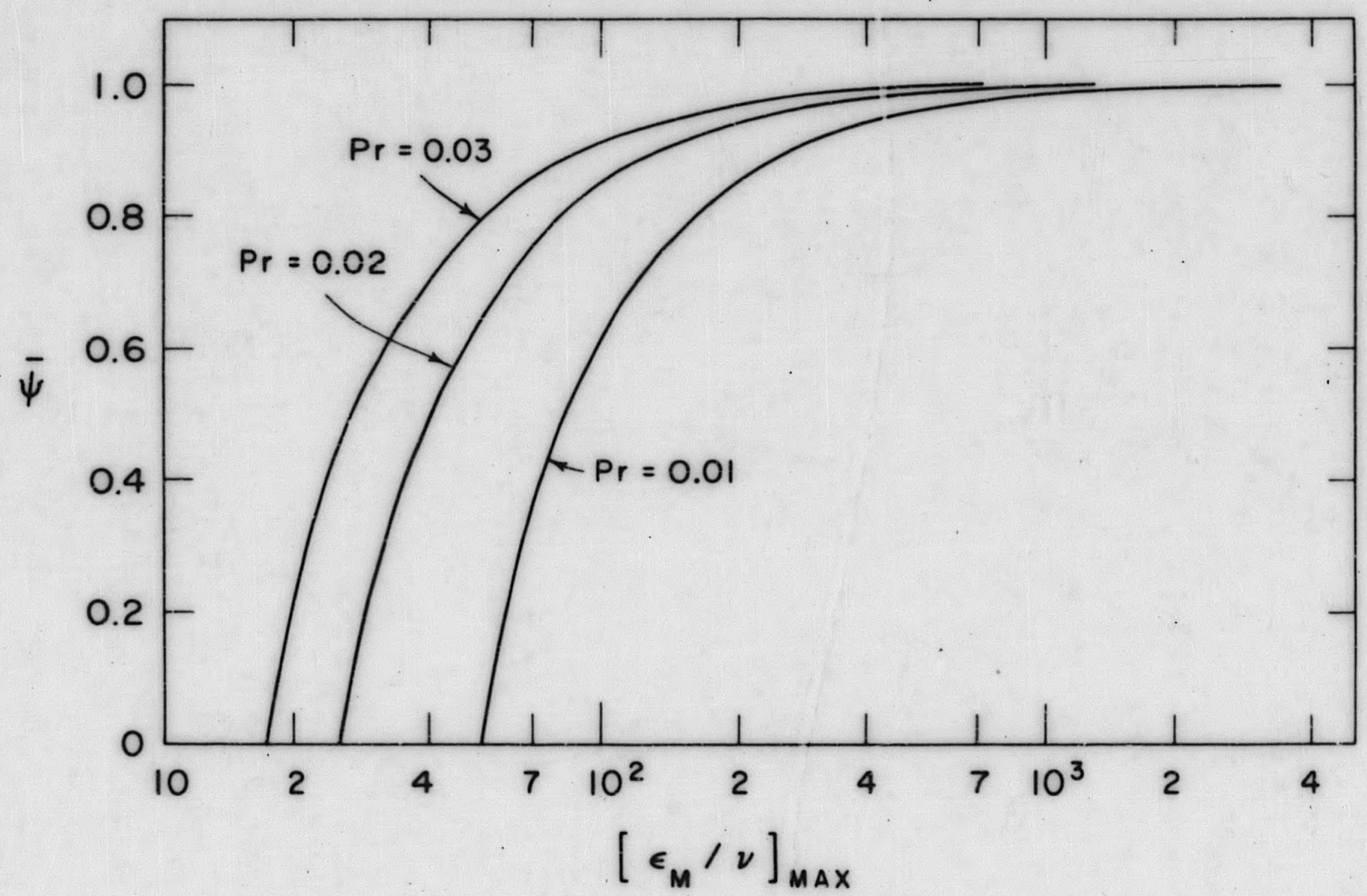

RN NES NO $3-340-62$ 


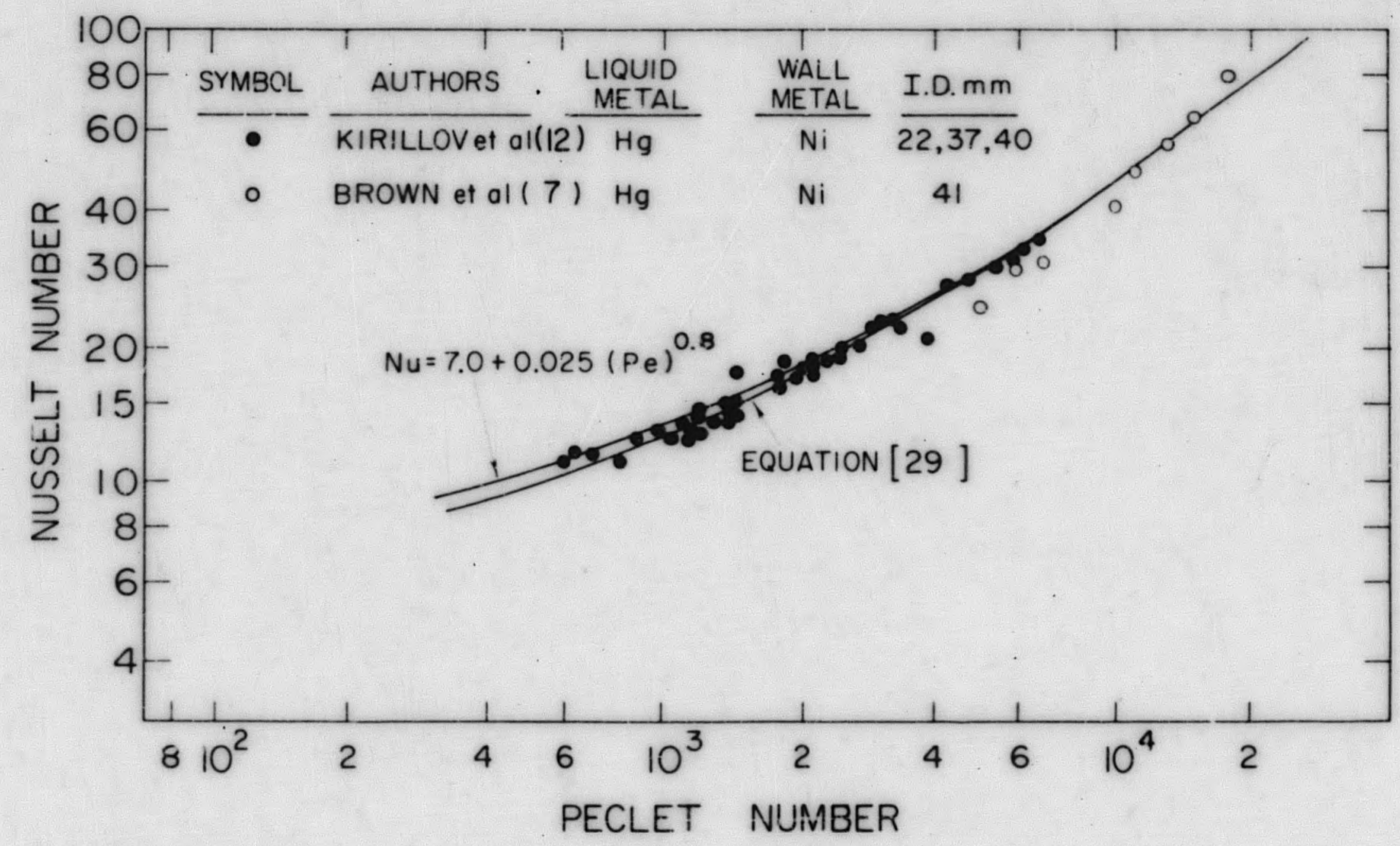

BNL Ne' No.3-3.36-62 


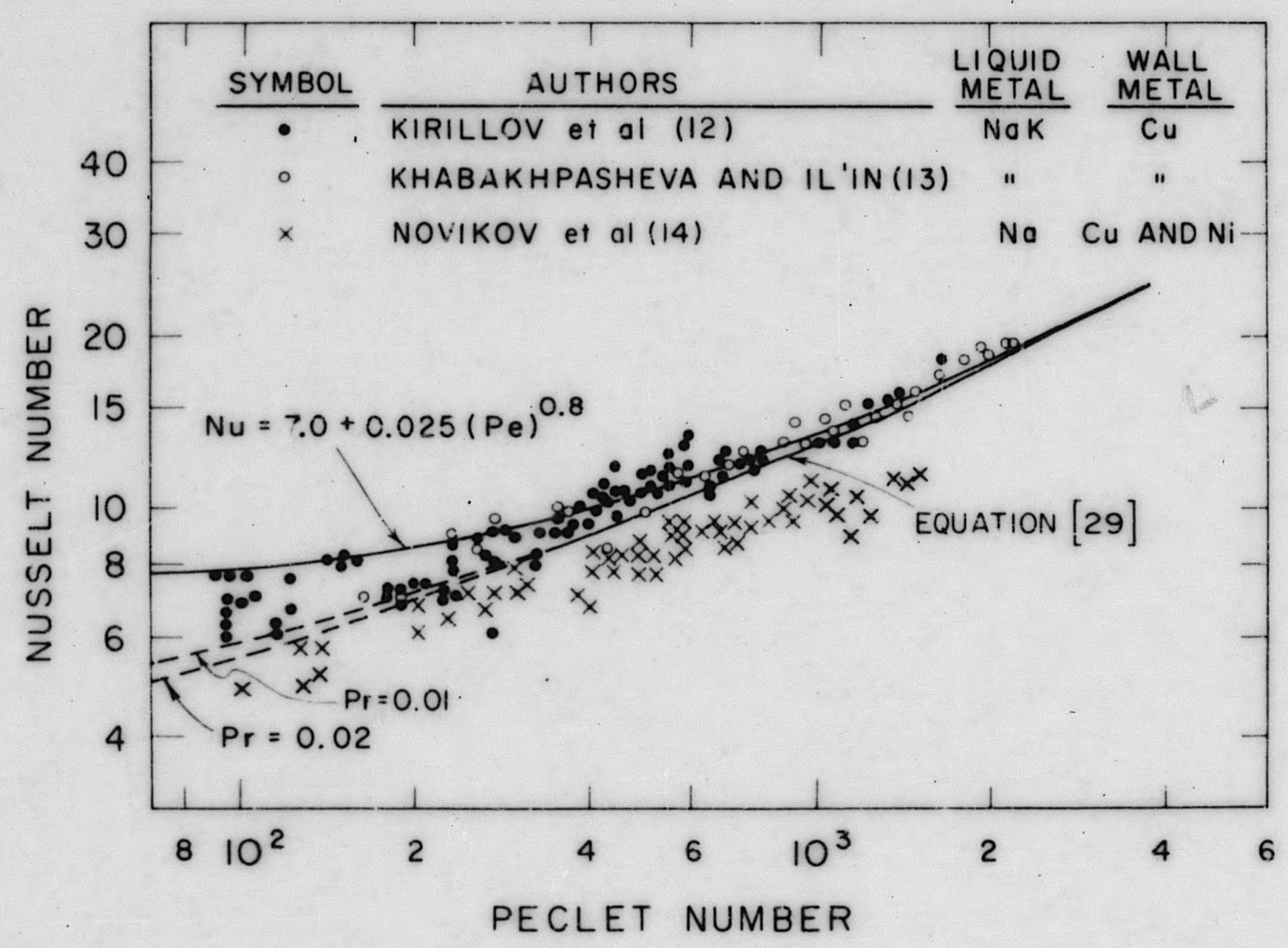

BNL NEY No 3-337-62 


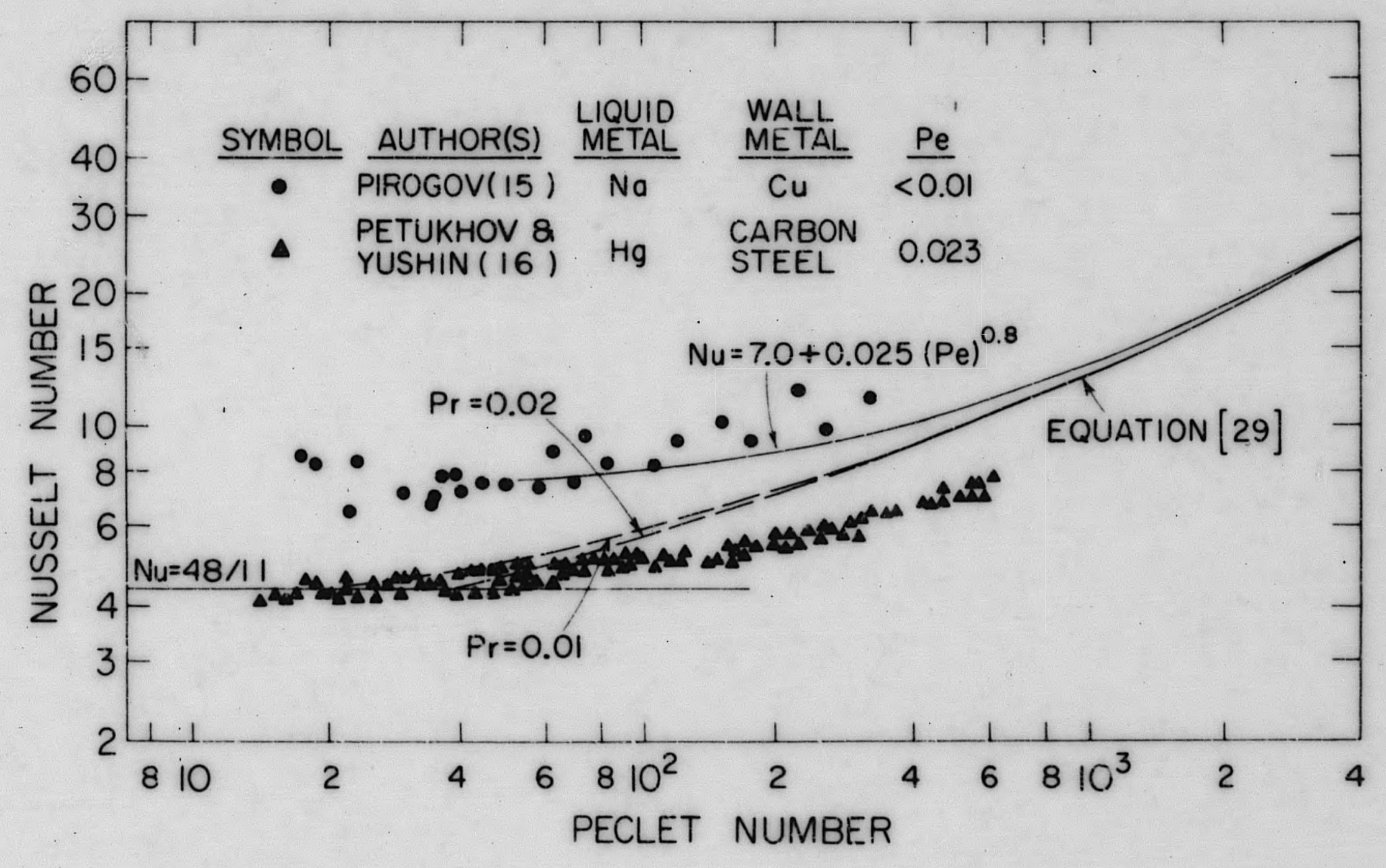

2NL NE9.NO 3- NBS-6: 


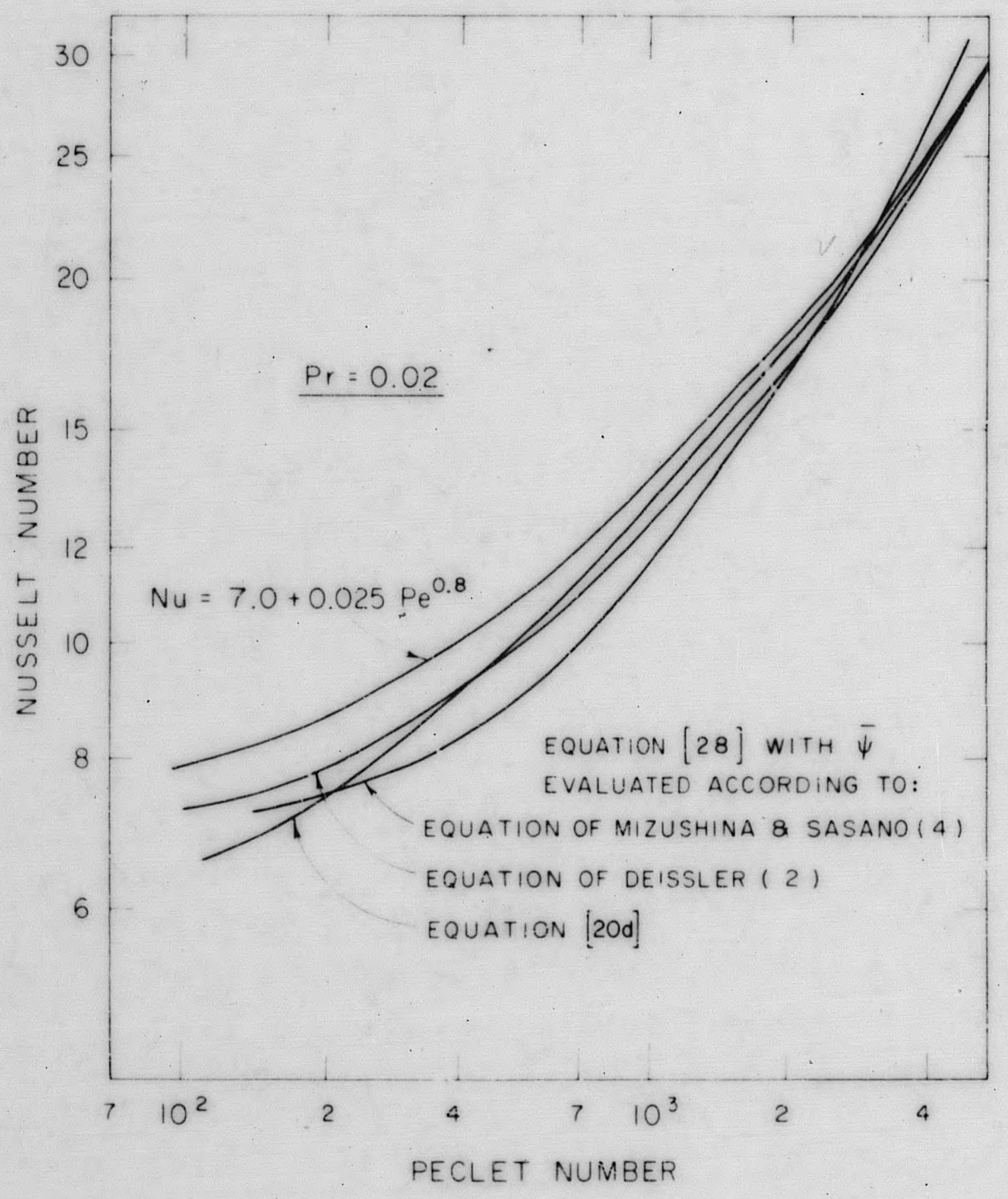

syos

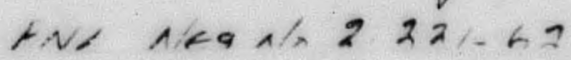




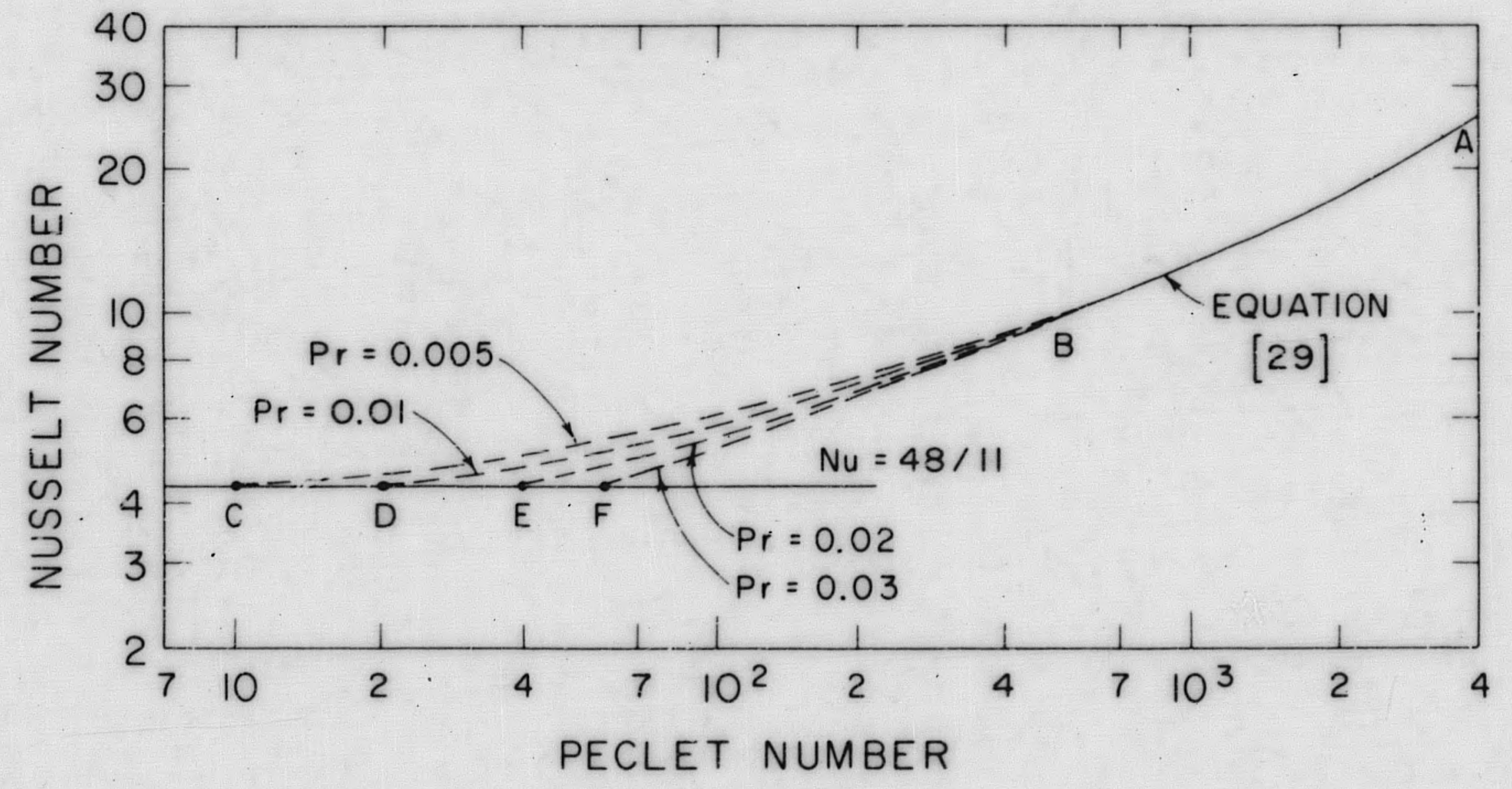

INI NE9 No $3-3.3 .5-62$ 


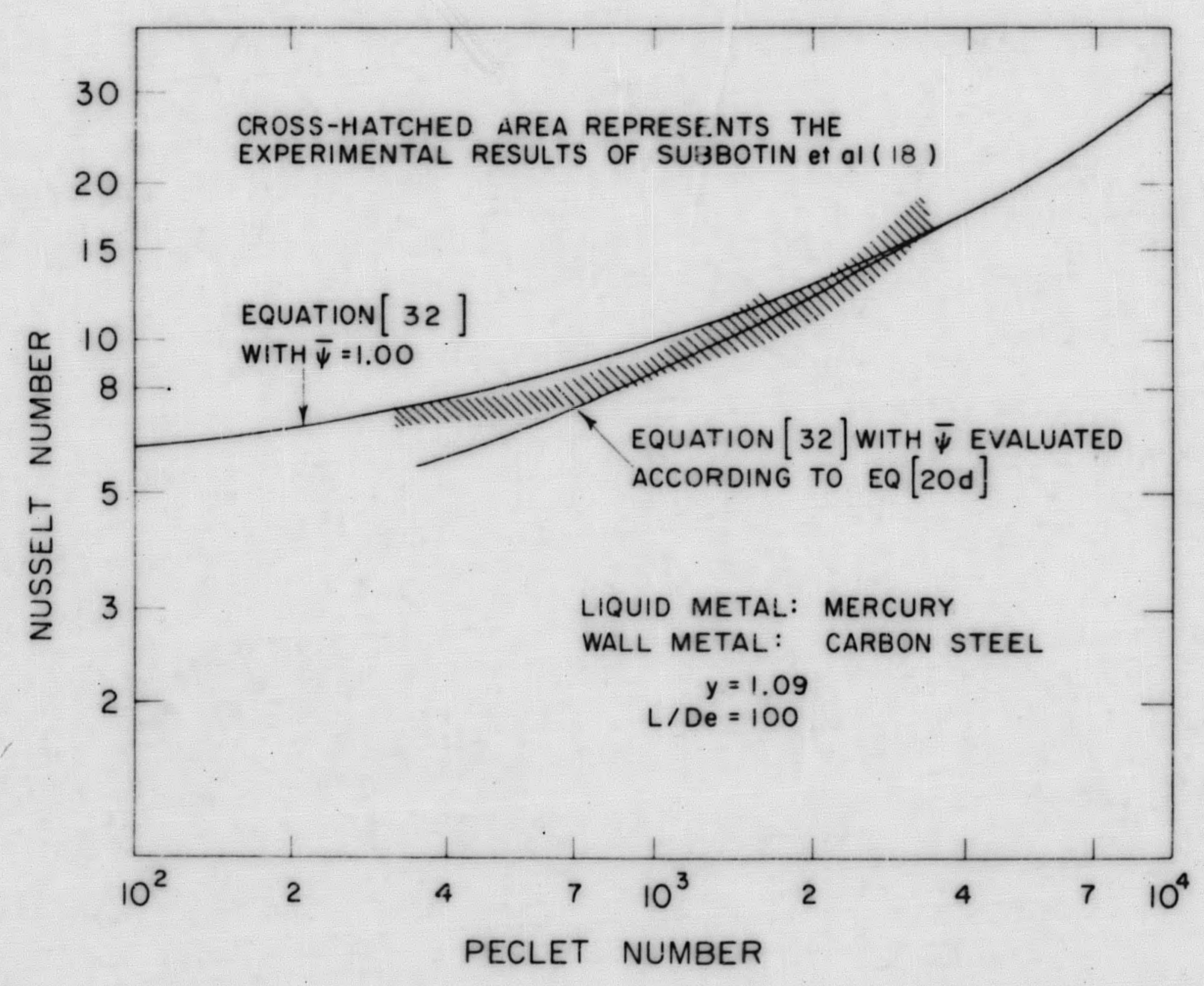

RNI NEQ No $2-33 n-62$ 


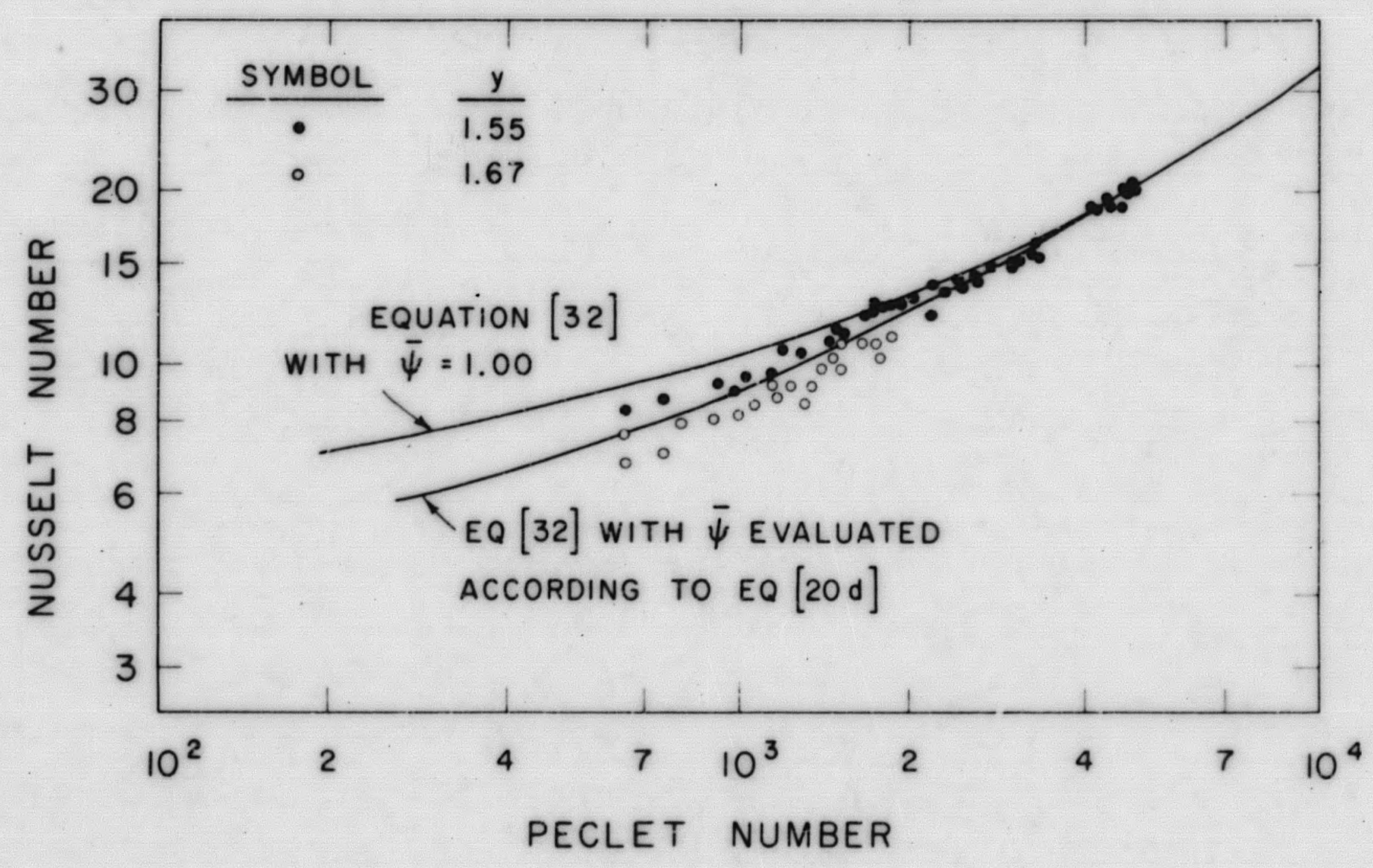

Ga) 1/C, 1/2 2-272-6: 




ANC NE9 No 3-336-62 


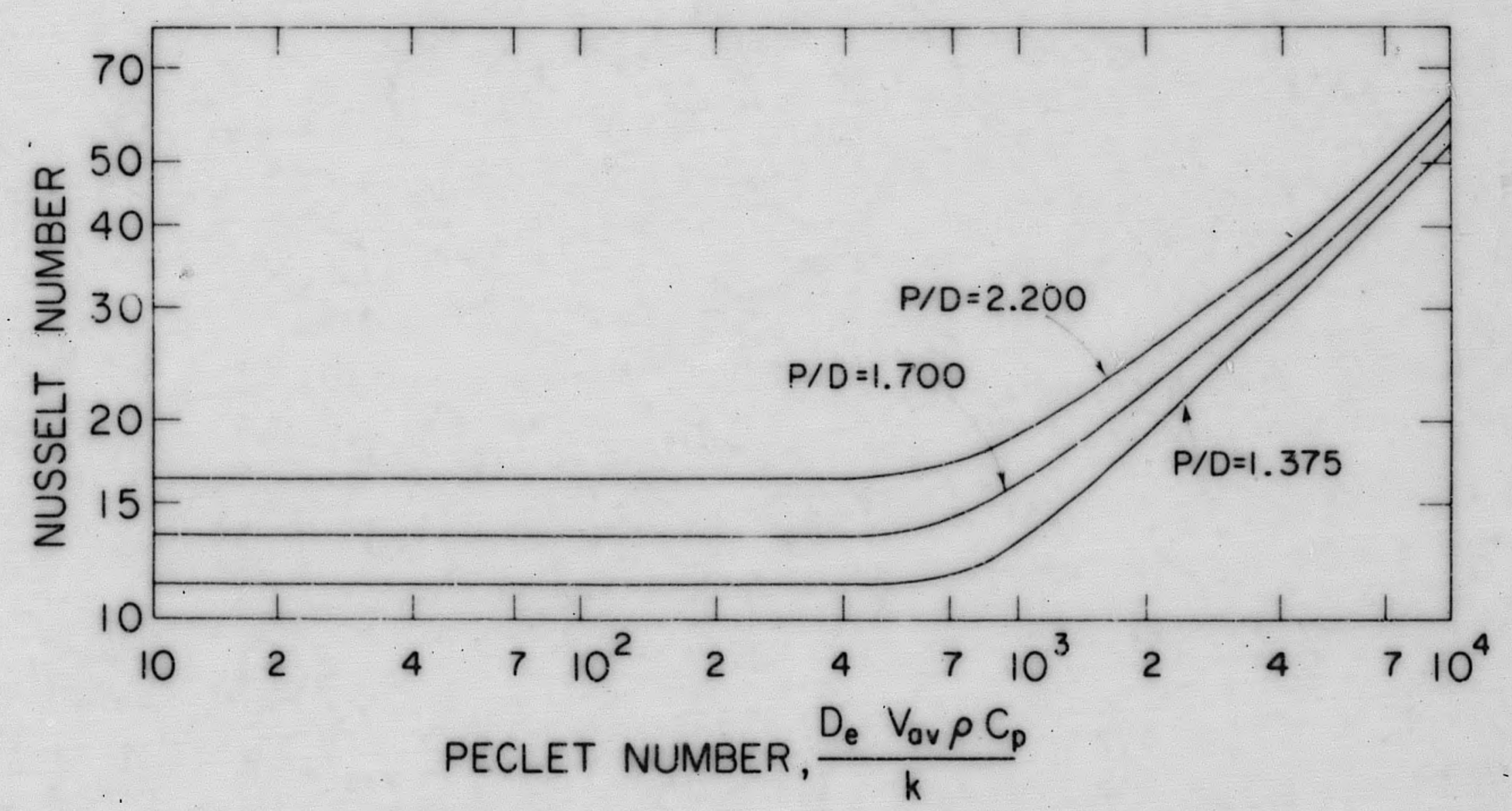




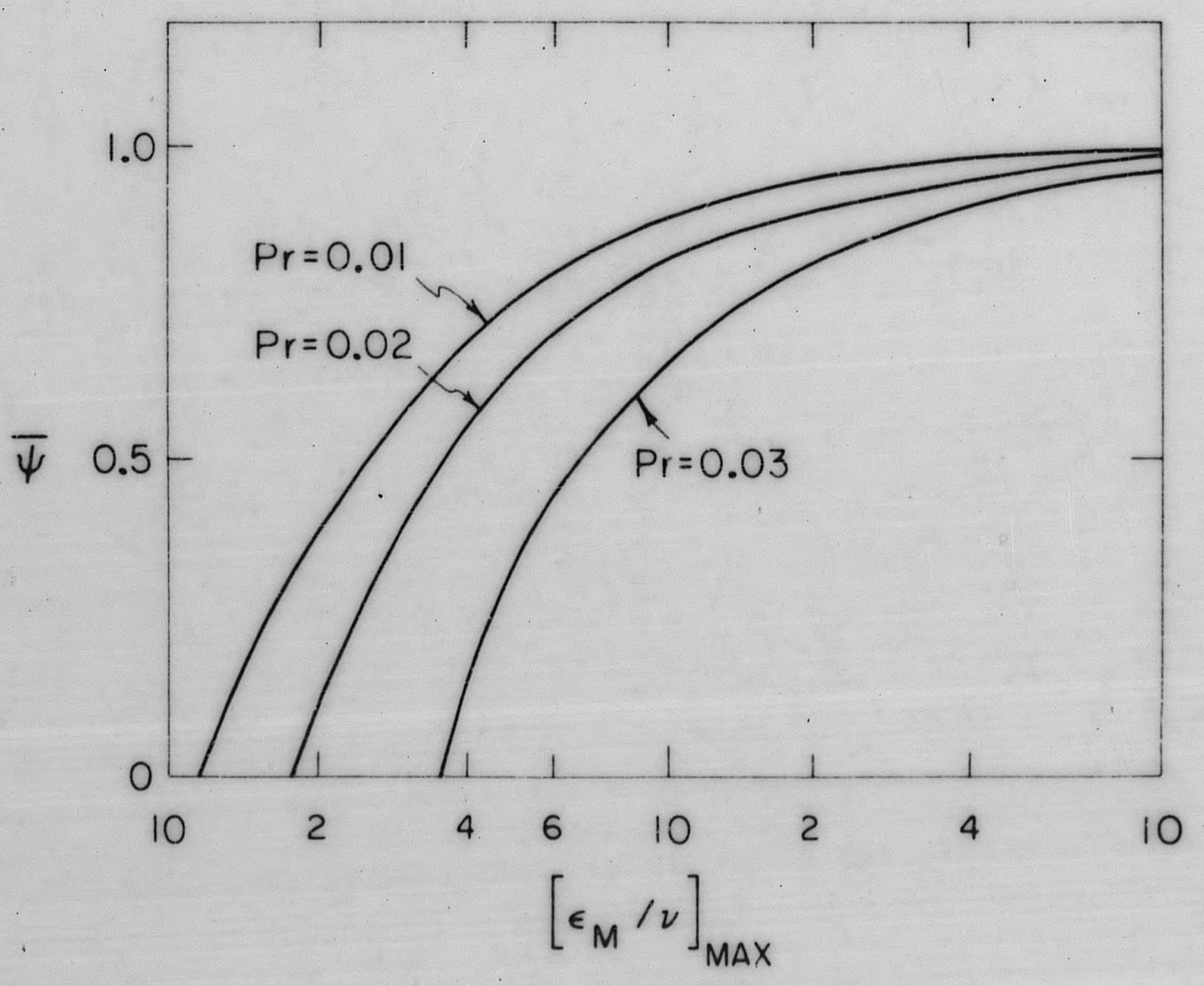




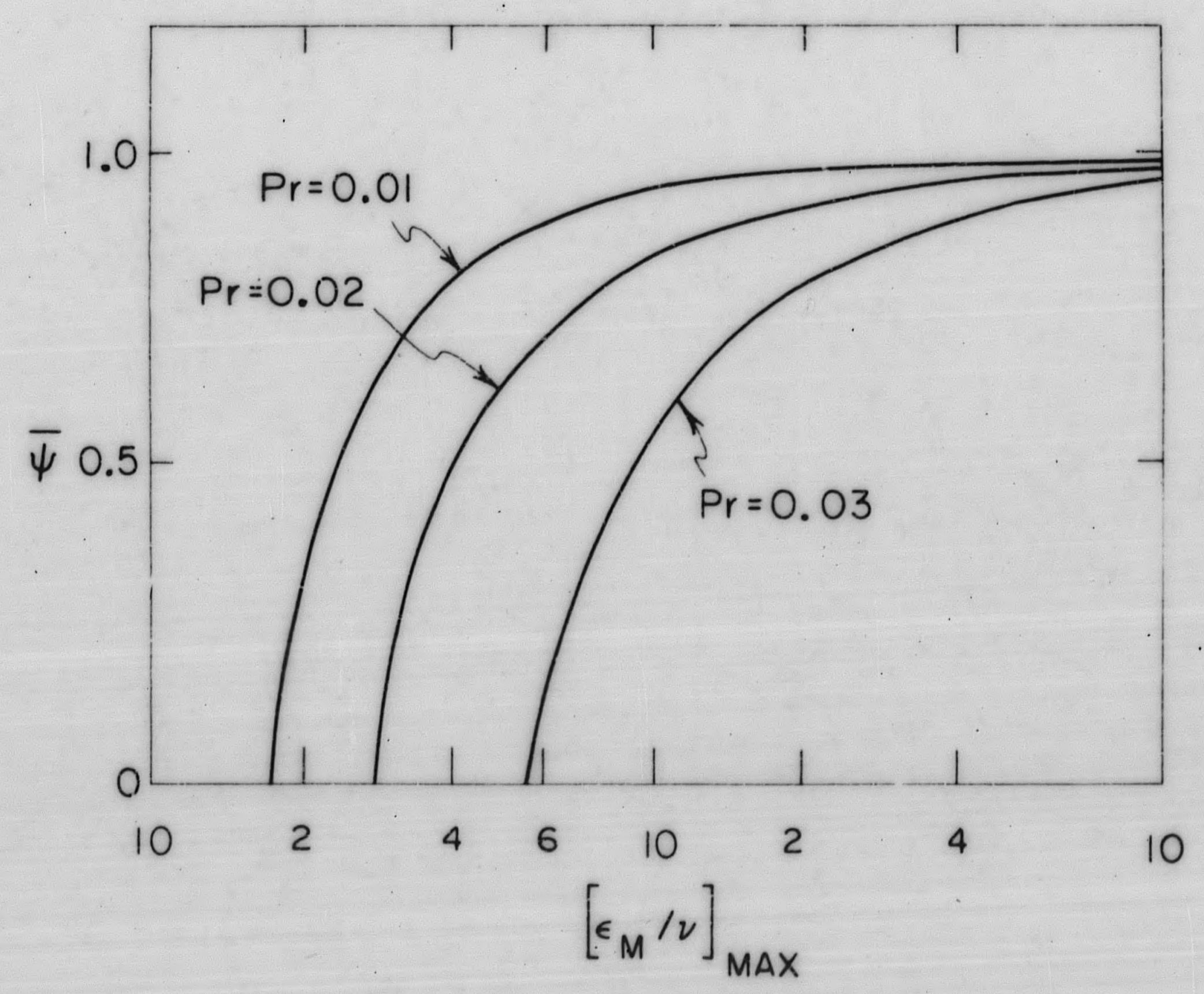

RAII $1 / 401 / 2 \times-2=9<$ 

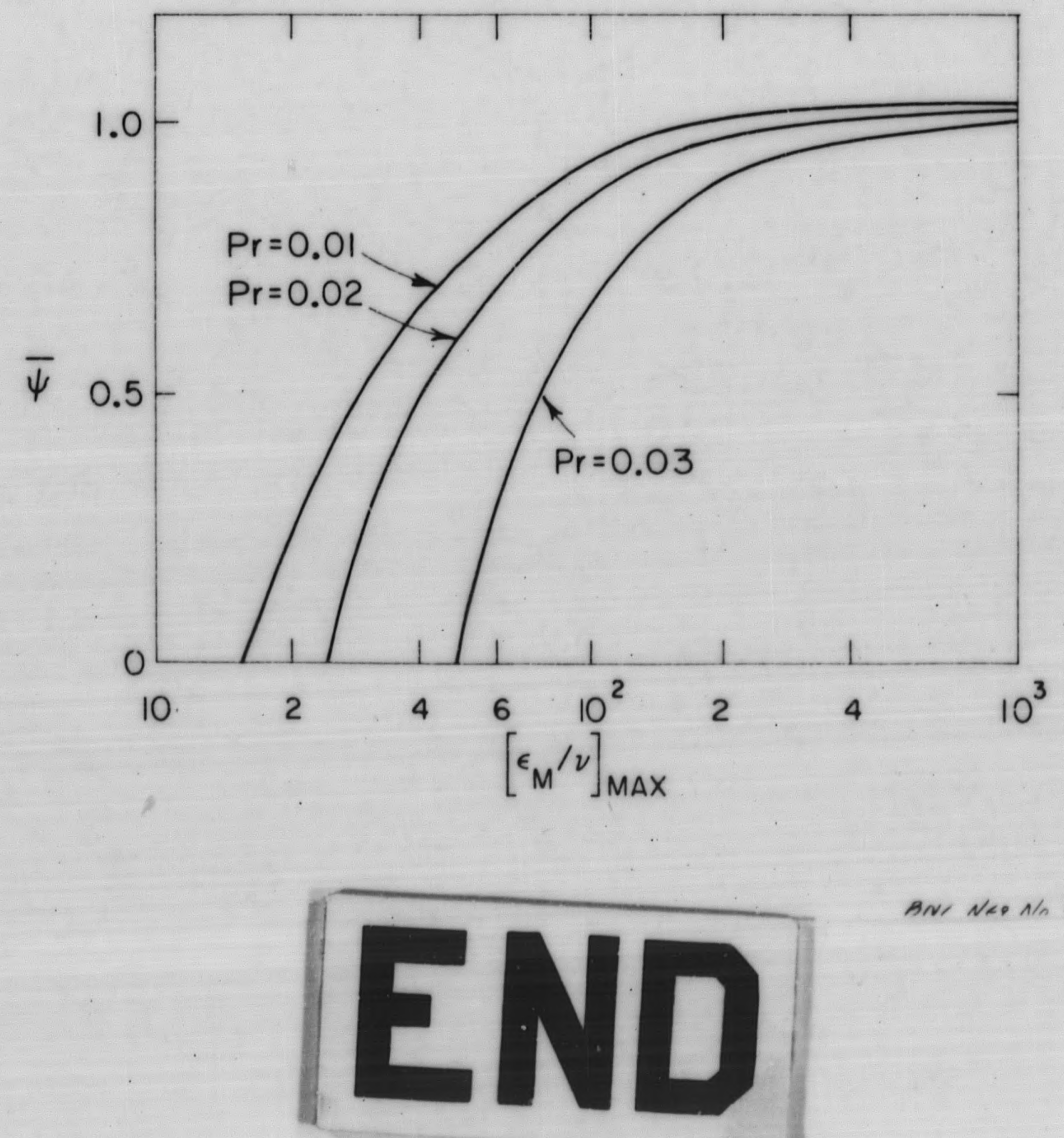

ANI NEQ 1/n 2-746-6 